\title{
Anatomy and Pathophysiology of Spinal Cord Injury Associated With Regional Anesthesia and Pain Medicine 2015 Update
}

\author{
Joseph M. Neal, MD, * Sandra L. Kopp, MD, † Jeffrey J. Pasternak, MD, † \\ William L. Lanier, MD, $\dagger$ and James P. Rathmell, MD
}

\begin{abstract}
Background and Objectives: In March 2012, the American Society of Regional Anesthesia and Pain Medicine convened its second Practice Advisory on Neurological Complications in Regional Anesthesia and Pain Medicine. This update is based on the proceedings of that conference and relevant information published since its conclusion. This article updates previously described information on the pathophysiology of spinal cord injury and adds new material on spinal stenosis, blood pressure control during neuraxial blockade, neuraxial injury subsequent to transforaminal procedures, cauda equina syndrome/local anesthetic neurotoxicity/arachnoiditis, and performing regional anesthetic or pain medicine procedures in patients concomitantly receiving general anesthesia or deep sedation.
\end{abstract}

Methods: Recommendations are based on extensive review of research on humans or employing animal models, case reports, pathophysiology research, and expert opinion.

Results: The pathophysiology of spinal cord injury associated with regional anesthetic techniques is reviewed in depth, including that related to mechanical trauma from direct needle/catheter injury or mass lesions, spinal cord ischemia or vascular injury from direct needle/catheter trauma, and neurotoxicity from local anesthetics, adjuvants, or antiseptics. Specific recommendations are offered that may reduce the likelihood of spinal cord injury associated with regional anesthetic or interventional pain medicine techniques.

Conclusions: The practice advisory's recommendations may, in select cases, reduce the likelihood of injury. However, many of the described injuries are neither predictable nor preventable based on our current state of knowledge.

What's New: Since publication of initial recommendations in 2008, new information has enhanced our understanding of 5 specific entities: spinal stenosis, blood pressure control during neuraxial anesthesia, neuraxial injury subsequent to transforaminal techniques, cauda equina syndrome/local anesthetic neurotoxicity/arachnoiditis, and performing regional anesthetic or pain procedures in patients concomitantly receiving general anesthesia or deep sedation.

(Reg Anesth Pain Med 2015;40: 506-525)

njury to the neuraxis associated with regional anesthesia or pain medicine procedures is ultimately linked to anatomic and/or

From the *Department of Anesthesiology, Virginia Mason Medical Center, Seattle, WA; †Mayo Clinic College of Medicine, Rochester, MN; and

tHarvard Medical School, Boston, MA.

Accepted for publication June 3, 2015.

Address correspondence to: Joseph M. Neal, MD, 1100 9th Ave (B2-AN), Seattle, WA 98101 (e-mail: Joseph.Neal@virginiamason.org).

Portions of this article were presented as a part of the American Society of Regional Anesthesia and Pain Medicine's second Practice Advisory on Neurological Complications in Regional Anesthesia and Pain Medicine in

San Diego, California, on March 16, 2012.

This study has no funding sources.

The authors declare no conflict of interest.

Copyright (C) 2015 by American Society of Regional Anesthesia and Pain Medicine

ISSN: 1098-7339

DOI: 10.1097/AAP.0000000000000297 physiologic damage to the spinal cord, the spinal nerve roots, or their blood supply. Mechanisms of injury are sometimes identifiable, as in the case of epidural hematoma or abscess, but can also be exceedingly difficult to pinpoint, as exemplified by most cases of presumed spinal vascular injury. The goal of our original advisory on this topic and the updated material contained herein is to provide an anatomic and pathophysiologic basis from which to build an understanding of neuraxial complications associated with regional anesthesia and pain medicine.

Consistent with a recent editorial call to focus practice advisory and consensus conference updates on new material, ${ }^{1}$ we have crafted this review in 2 sections. First, to provide perspective, we will briefly review those topics and associated recommendations for which no substantially new knowledge has emerged. To provide consistency over time or when appropriate, the current review will present text and especially recommendations that are essentially verbatim from those of our original work. Interested readers can find the detailed explanations and their specific literaturebased citations by revisiting those 2008 articles. ${ }^{2,3}$ The second section will focus on 5 topics that either have significantly new information to add to our previous understanding and/or we believe deserve more extensive discussion than was provided in the first iteration of this practice advisory.

\section{METHODS}

Standard search engines and cross-referenced citations identified the literature basis for the updated material contained within this review. PubMed and Ovid were searched from 2006 forward to identify new material by using MeSH terms as individual headings or in relevant combinations: "spinal cord injury," "hypotension," "neurotoxicity," "transforaminal," "cauda equina syndrome," "anterior spinal artery syndrome," "needle injury," "spinal stenosis," "spinal cord ischemia," and "spinal cord infarction."

As specifically noted in our 2008 review, "The strength of scientific evidence that is used to arrive at these recommendations is not easily measured by traditional stratification methodologies such as the United States Agency for Health Care Policy and Research structure for ranking Statements of Evidence and Grades of Recommendation. ${ }^{4}$ Because of the extreme rarity of the specific complications that are addressed in this article, traditional methodologies such as randomized controlled trials, meta-analysis, or large human case series rarely exist and are unlikely to exist in the future. Our recommendations are therefore based on methodologies that are necessarily less robust, such as anatomic or pathophysiologic studies of human cadavers or animals, nonrandomized trials, retrospective series, case reports, or expert opinion. The grading of recommendations offered by this practice advisory has been modified from an American College of Cardiology/American Heart Association construct that classifies the strength of guidelines for perioperative cardiac evaluation." 2

Readers of this article are reminded that practice advisories are created when data on a subject are limited or nonexistent. 
Advisories rely on limited clinical and animal data, and as such, the synthesis and interpretation of data by 1 group of experts may differ from conclusions by another set of equally qualified experts. Thus, practice advisories represent a level of recommendation that is less than that offered by standards or clinical practice guidelines. ${ }^{5}$ The recommendations contained herein do not define standard of care. They are not intended to replace clinical judgment as applied to a specific patient scenario. "These recommendations are intended to encourage optimal patient care, but cannot ensure the avoidance of adverse outcomes. As with any practice advisory recommendation, these are subject to revision as knowledge of specific complications advances."

\section{REVIEW OF PREVIOUS RECOMMENDATIONS}

\section{Mechanical Injury}

Some neuraxial anesthetic complications are secondary to mechanical injury of the spinal cord, spinal nerve roots, or the spinal nerves as they exit the intervertebral foramina. Injury to these structures may involve direct needle or catheter trauma or lesions within the vertebral canal that compress neural structures and thereby cause ischemic injury. These various mechanisms ultimately lead to loss of anatomic and/or physiologic neural integrity and can result in permanent injury. ${ }^{7}$ We have not changed the majority of recommendations related to mechanical injury (Table 1).

\section{Iatrogenic Spinal Cord Trauma}

The incidence of spinal cord-related needle/catheter trauma is unknown, but decidedly rare. Anesthesiologist-reported or qualityassurance databases may well underreport this complication, whereas medicolegal databases are likely to skew data in the opposite direction. For instance, direct spinal cord injury was noted in $6(0.73 \%)$ of 821 neuraxial claims from the American Society of
Anesthesiologists (ASA) Closed Claims database, which does not provide a denominator of total cases. ${ }^{7}$ Conversely, direct needle trauma was detected in only 9 of 1.7 million neuraxial anesthetics $(0.0005 \%)$ over a 10 -year period in Sweden, ${ }^{12}$ and only 1 case was reported in a 2000 survey from French spinal cord rehabilitation centers (from an estimated 1 million neuraxial anesthetics performed that year in their catchment area). ${ }^{13}$

Three anatomic characteristics of the human neuraxis contribute to its potential for sustaining needle or catheter injury. First, although the conus medullaris is typically described as terminating at the L1-2 vertebral interspace in adults (and terminates more caudad in the first few months of life), its terminus varies widely from T12 to L4. When this variation is coupled with practitioners' inaccurate determination of which spinal interspace they are palpating, ${ }^{14}$ it is not surprising that needle injury to the spinal cord has been reported in instances where the conus medullaris terminated more caudad than expected. ${ }^{12}$ Indeed, a recent study demonstrated that in $40 \%$ of term parturients, the perceived vertebral level identified by palpation at the intercristal line was in reality at the L3 interspace or higher. ${ }^{15}$ Neuraxial ultrasonography may improve estimation of the vertebral level because it is more accurate than palpation for identifying surface landmarks, especially in challenging anatomic scenarios, ${ }^{16}$ such as obesity, scoliosis, or previous spinal surgery. ${ }^{17}$ Second, the customary expectation of encountering resistance prior to entering the epidural space is not always fulfilled in those individuals in whom the ligamentum flavum has failed to fuse in the midline, a condition that is more prominent in the upper thoracic (4\%-21\% midline gaps at T3-4 and above) and cervical neuraxis (51\%-74\% midline gaps). ${ }^{18} \mathrm{Un}$ anticipated congenital dysraphisms can also contribute to accidental entry into the spinal cord. ${ }^{19}$ Third, the margin for error during needle advancement is significantly diminished as one proceeds from the lumbar posterior epidural space with its 5- to $13-\mathrm{mm}$ dorsal-to-ventral dimensions, to the 2- to 4-mm thoracic posterior epidural space, to the average $0.4-\mathrm{mm}$ cervical posterior epidural

TABLE 1. Recommendations: Factors That May Limit Neuraxial Injury

These recommendations are intended to encourage optimal patient care, but cannot ensure the avoidance of adverse outcomes. As with any practice advisory recommendation, these are subject to revision as knowledge advances regarding specific complications.

\section{Anatomic factors}

- Misidentification of vertebral level, unrecognized lateral needle placement or deviation, abnormal caudad termination of the spinal cord, or failure of the ligamentum flavum to fuse in the midline may contribute to direct needle injury of the spinal cord. Clinicians are advised to be aware of these anatomic conditions, particularly in patients with challenging surface anatomy (eg, as may occur with obesity, kyphoscoliosis, and other conditions). Ultrasonography or fluoroscopy could be considered as an adjunct for accurate determination of vertebral level in these challenging patients. (Class I)

- Surgical positioning, severe spinal stenosis, and specific space-occupying extradural lesions (eg, epidural lipomatosis, ligamentum flavum hypertrophy, synovial cysts, or ependymoma) have been associated with temporary or permanent spinal cord injury in conjunction with neuraxial regional anesthetic techniques. These conditions are particularly relevant when they coexist with an epidural hematoma or abscess. Awareness of these conditions should prompt consideration of risk-versus-benefit when contemplating neuraxial regional anesthetic techniques. (Class I)

- Patients with known tumor in the epidural space should undergo neuraxial imaging studies to define the extent of tumor mass. If the tumor is close to the planned site of epidural solution injection, alternative methods of anesthesia or analgesia should be considered. (Class II)

- For patients receiving neuraxial injection for treatment of pain (eg, cervical epidural injection of steroids via an interlaminar route), radiologic imaging studies such as computed tomography (CT) or magnetic resonance imaging should be used to assess the dimensions of the spinal canal, and this information should be considered in the overall risk-to-benefit analysis as well as guiding the selection of the safest level for entry. (Class II)

Physiologic factors

- Clinicians are advised to be aware of and to avoid conditions that have been linked to the formation of epidural hematoma or epidural abscess, as noted in previous American Society of Regional Anesthesia and Pain Medicine Practice Advisories. Such conditions include concurrent or imminent anticoagulation, the use of multiple anticoagulants, improper aseptic technique, and needle placement during untreated active infection. $^{8-11}$ (Class I)

Recommendations contained within Table 1 have been modified minimally from the authors' 2008 advisory. ${ }^{2}$ Significant changes are in italics. 
space. Indeed, because the epidural space is a potential space, the cervical posterior epidural space may be nonexistent, particularly at higher vertebral levels. ${ }^{20-22}$

Mass lesions can also lead to spinal cord injury. Intradural or extradural lesions compete for cross-sectional space within the spinal canal and in so doing potentially decrease spinal cord perfusion pressure (SCPP) by inhibiting arterial inflow, inhibiting venous outflow, or elevating cerebrospinal fluid (CSF) pressure $\left([\mathrm{SCPP}=\text { mean arterial pressure }- \text { spinal cord CSF pressure }]^{23}\right.$; in rare circumstances, direct venous outflow pressure may also impact regional SCPP.) If SCPP is sufficiently diminished, it can lead to spinal cord ischemia that in more severe instances can produce infarction. Epidural hematoma and abscess are commonly recognized complications of neuraxial anesthetic or pain medicine techniques, and they can lead to consequential mass lesions. ${ }^{8,24}$ Less well appreciated is the potential for transient pressure elevations secondary to excessive volumes of local anesthetic ${ }^{25}$ (especially in infants), ${ }^{26}$ compromised egress of local anesthetic or blood through stenotic intervertebral foramina, ${ }^{27}$ or unusual mass lesions such as tumors, granulomas from chronic intrathecal morphine administration, ${ }^{28}$ epidural lipomatosis, ${ }^{29,30}$ synovial cysts, ${ }^{13}$ or ependymoma. Many of these conditions are occult to patient and practitioner and become relevant only when blood, pus, or local anesthetic competes for limited cross-sectional area within the vertebral canal. The presence of increased volume within the vertebral canal, whether by fluids or mass lesions, can have a "Starling resistor" effect on blood vessels, limiting blood ingress into and egress from the affected tissues. Moreover, patients with severe spinal stenosis or other mass effects may be at additional risk of compromised tissue blood flow when surgical field exposure requires certain positions such as extreme lordosis, lithotomy, or the flexed lateral position. ${ }^{2,31}$

\section{Spinal Nerve Root and Spinal Nerve Trauma}

The spinal nerves are protected during midline or paramedian approaches to the neuraxis because of their lateral position and the partial protection afforded by the vertebral laminae, transverse processes, and facet joints. Therefore, midline procedurerelated injury to the spinal nerve, or to the anterior or posterior ramus outside the intervertebral foramen, occurs only when needles deviate laterally. Spinal nerves can also be contacted unintentionally during procedures such as paravertebral or psoas compartment block when the needle is directed too medially. Needles medial to the facet within the lateral recess may unintentionally contact the dorsal nerve roots $^{2}$ (Fig. 1).

As concluded in our 2008 review, "mechanical injury to the neuraxis can arise consequent to direct needle trauma or to spaceoccupying lesions whose mass effect compromises spinal cord blood flow (SCBF). Evidence to support contribution to injury varies with the mechanism of injury. In the case of epidural hematoma or abscess, extensive literature supports causation. Conversely, neuraxis injury in the setting of rare extraspinal mass lesions or relatively common surgical positions only establishes association or chance occurrence." ${ }^{2}$ Limited additional information since our 2008 publication has not altered this conclusion (Table 1), except for new information on the association of spinal stenosis with neuraxial injury, as will be presented subsequently.

\section{Spinal Cord Ischemia and Vascular Injury}

Disruption of SCBF can occur from a variety of mechanisms, including needle trauma affecting the spinal vasculature (Fig. 2), compressive mass lesions (Fig. 3), or vascular spasm (Fig. 4). Spinal cord blood flow may also be compromised from low-flow states, such as might occur from significant and prolonged systemic hypotension, embolic phenomena, or vascular stenosis. The frequency of spinal cord ischemia is distinctly rare and our understanding limited. Our previous article ${ }^{2}$ extensively reviewed the human spinal cord blood supply. The spinal cord and cauda equina receive two-thirds of their blood supply from the anterior spinal artery, which cannot be injured directly by midline or paramedian needles without first traversing the spinal cord (Fig. 2). Damage to the spinal cord's posterior blood supply is largely mitigated by the redundancy of the posterior spinal artery system. However, the segmental or spinal branch arteries are exposed to needle-related trauma when the needle deviates far laterally or is intentionally placed near a segmental artery (such as during perispinal techniques or celiac plexus block). ${ }^{33}$ Radicular arteries can sustain needle injury during a transforaminal approach, which can be important if that artery is 1 of the few radicular arteries that continue on to become a medullary artery supplying the spinal cord (Fig. 5). Disruption of SCBF might also occur from procedure-induced hematoma or drug-induced vasospasm associated with neurolytic procedures such as celiac plexus block (Fig. 4), although clear proof of these mechanisms is lacking. ${ }^{2}$

Within the category of vascular injury to the neuraxis, the majority of our previous recommendations remain intact (Table 1). However, we will henceforth discuss 2 topics for which new information justifies strengthening of previous advice: blood pressure control during neuraxial anesthesia and central nervous system (CNS) injury during transforaminal pain medicine procedures.

\section{Neurotoxicity}

Our previous review concluded, "Neuraxial local anesthetics, opioids, adjuvants, and preservatives in clinically recommended doses are remarkably safe in the vast majority of patients. Nevertheless, a patient may rarely be vulnerable to local anesthetic and adjuvant neurotoxicity even in normal clinical situations. Clinical evidence comes from case reports of patients who sustained neuraxis injury that was presumed secondary to a neurotoxic mechanism, even though they received standard doses of spinal or epidural local anesthetic with or without adjuvant. Neurotoxicity is more likely to occur in conjunction with physical disruption of the blood-spinal cord barrier by needle or catheter trauma, or from iatrogenic conditions leading to maldistribution and/or overdosing of neuraxial local anesthetics." ${ }^{2}$ While our previous recommendations have not substantially changed (Table 1), we will henceforth discuss newer information concerning cauda equina syndrome (CES), arachnoiditis, and clinical experience with intrathecal 2-chloroprocaine (2-CP).

\section{NEW RECOMMENDATIONS FROM THE SECOND PRACTICE ADVISORY}

\section{Spinal Stenosis}

Spinal hematoma, abscess, tumor spread, epidural lipomatosis, spinal arachnoid cysts, ankylosing spondylitis, ${ }^{12,34}$ or extreme surgical positioning such as hyperlordosis or extreme lateral flexion ${ }^{31,35}$ are mechanical causes that can contribute to the development of spinal cord ischemia or infarction in the perioperative period. Recent literature has focused on degenerative spinal stenosis and its association with various manifestations of neuraxial injury in the setting of regional anesthesia. Degenerative spinal stenosis is caused by osteoporosis and/or hypertrophy of the ligamentum flavum and bony elements of the spinal canal that effectively reduces spinal canal crosssectional area and competes with the spinal cord and nerve roots for space. Similar mechanisms might contribute to local anesthetic neurotoxicity by causing maldistribution and/or 


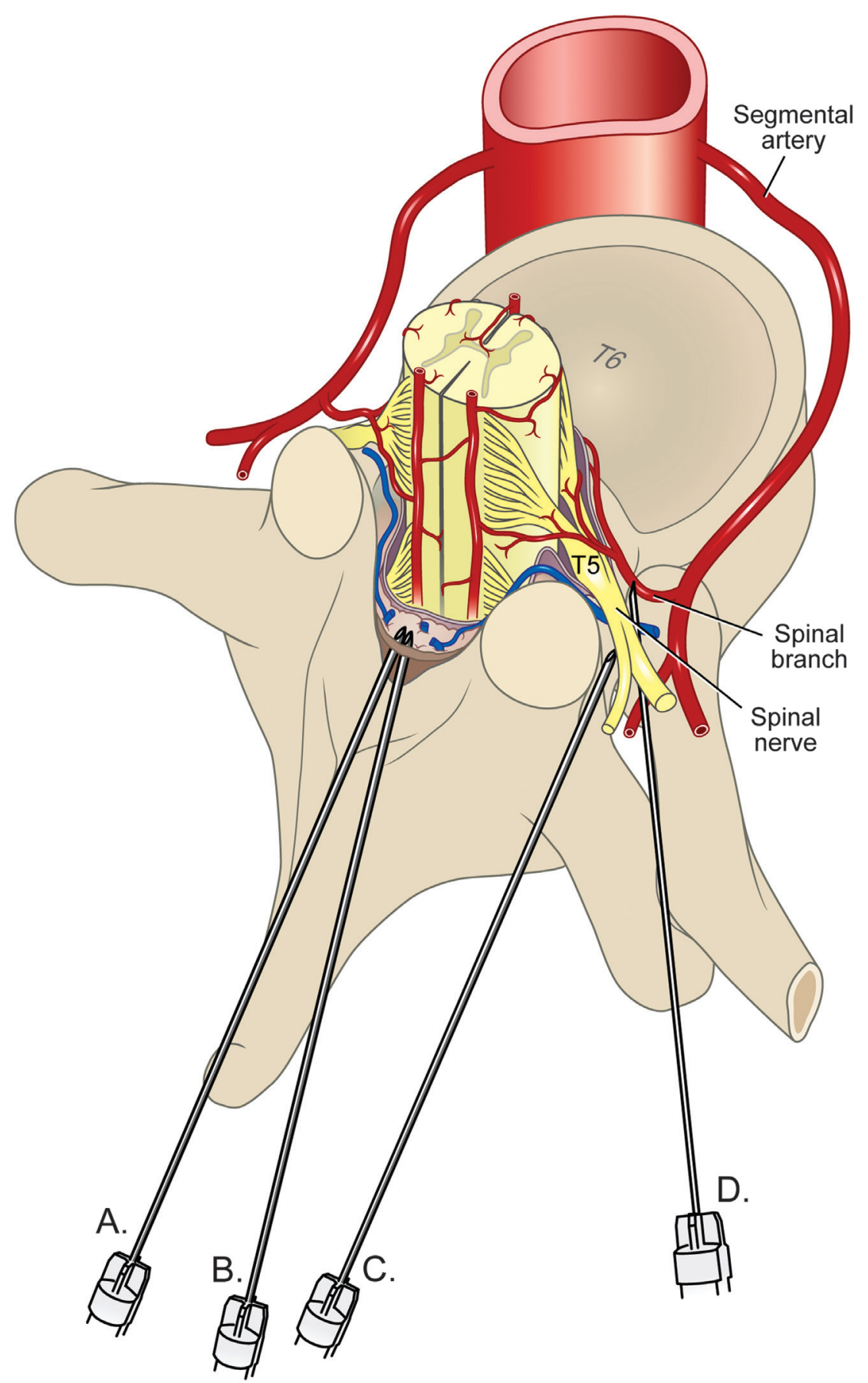

FIGURE 1. Midline or paramedian approaches (needles A and B) may directly traumatize the spinal cord, whereas unintentional lateral deviation of the needle (C) may contact the spinal nerve or the anterior or posterior primary ramus outside the foramen. Intentional lateral approaches, for example, transforaminal approach (needle D), have the potential to come in close proximity to the spinal nerve or a spinal artery. Note that transforaminal approaches are typically at the cervical or lumbar levels, not the T6 level as illustrated. Illustration by Gary J. Nelson. Reproduced with permission from Neal and Rathmell, Complications in Regional Anesthesia and Pain Medicine. ${ }^{32}$

reduced clearance of relatively undiluted drug. ${ }^{36,37}$ Degenerative changes may also cause narrowing of the vertebral foramina, which compromises egress of fluids ${ }^{22,38}$ and consequently results in an increase in vertebral canal pressure ${ }^{27}$ and transiently diminished neural blood flow. ${ }^{39}$ Spinal stenosis represents a continuum of severity, from mild and inconsequential to severe; $19 \%$ of patients in their 60 s will have absolute spinal stenosis $\left(<1-\mathrm{cm}\right.$ anteroposterior diameter of the spinal canal). ${ }^{40} \mathrm{Al}-$ though commonly discovered during imaging for the diagnosis of back pain, there are subsets of patients with undiagnosed spinal stenosis that is discovered only during workup of injury after a neuraxial anesthetic. ${ }^{12}$ 


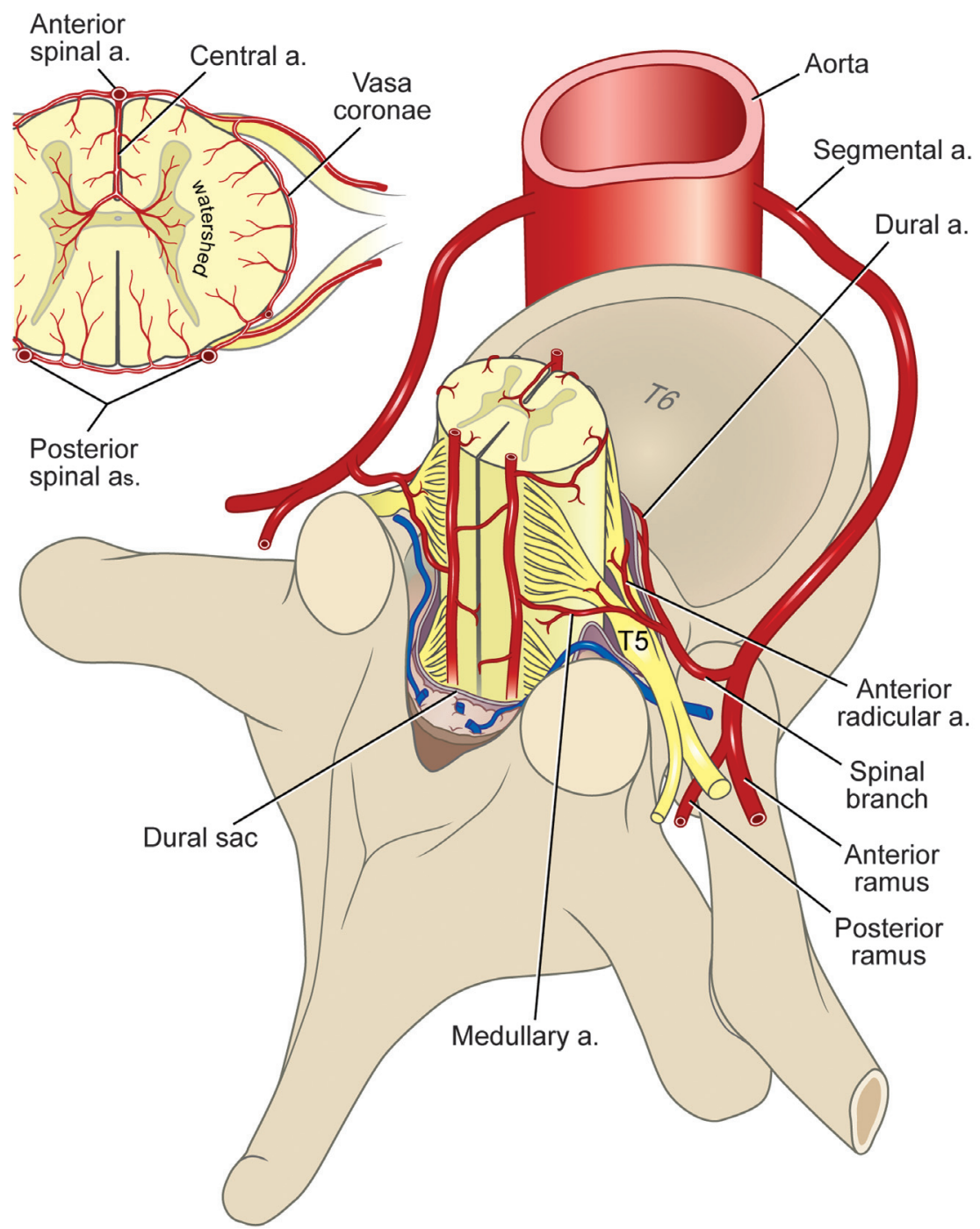

FIGURE 2. Midline or paramedian approaches may directly traumatize the posterior spinal arteries, whereas unintentional lateral deviation of the needle may contact the spinal branch artery. Direct injury to the anterior spinal artery would require placement of a needle or catheter through the spinal cord. Illustration by Gary J. Nelson. Reproduced with permission from Neal and Rathmell, Complications in Regional Anesthesia and Pain Medicine. ${ }^{32}$

The potential for spinal stenosis to cause or worsen neuraxial injury in the setting of a regional anesthetic has been the object of speculation for decades. ${ }^{41}$ However, the first strong signal of the relationship between spinal pathology and increased risk of neuraxial injury was identified in Moen and colleagues ${ }^{12}$ report of the association between spinal stenosis and neuraxial injury in 1.7 million neuraxial anesthetics conducted in Sweden between 1990 and 1999. Of the 33 cases of spinal hematoma, one-third were associated with coagulopathy or thromboprophylaxis (in onethird of those cases, thromboprophylaxis was administered in accordance with published guidelines). This report contrasted the extreme rarity of spinal hematoma in young women who received neuraxial anesthesia for childbirth $(1: 200,000)$ versus the $1: 22,000$ incidence of spinal hematoma in elderly women undergoing hip fracture repair or 1:3600 incidence in those elderly women receiving total joint arthroplasty. During diagnostic imaging, 6 of the 33 cases were noted to have previously undiagnosed spinal stenosis or ankylosing spondylitis. These conditions may have compromised spinal cord circulation to a greater extent in the mostly elderly women who constituted the majority of this cohort, as compared with younger obstetric patients with an uncompromised spinal canal who likely would have experienced a lesser degree of circulatory impairment from a similarly sized hematoma. ${ }^{12,42}$

Since the Swedish publication, confirmatory reports have emerged. ${ }^{13,43}$ For example, a retrospective analysis of neuraxial anesthetics performed in patients with known spinal canal pathology (spinal stenosis or lumbar disc disease) observed a $1.1 \%$ incidence of neuraxial complications, which was higher than expected for patients without spinal canal pathology who underwent similar surgeries at the same institution. ${ }^{44}$ While this study corroborates observations from previous investigations and points to a higher incidence in those patients with known spinal stenosis compared with those with unsuspected disease, it also points to the difficulties in firmly establishing spinal canal pathology and subsequent neuraxial injury as cause and effect, rather than association. Case reports and large registries do not provide a general anesthetic control group and cannot distinguish whether 


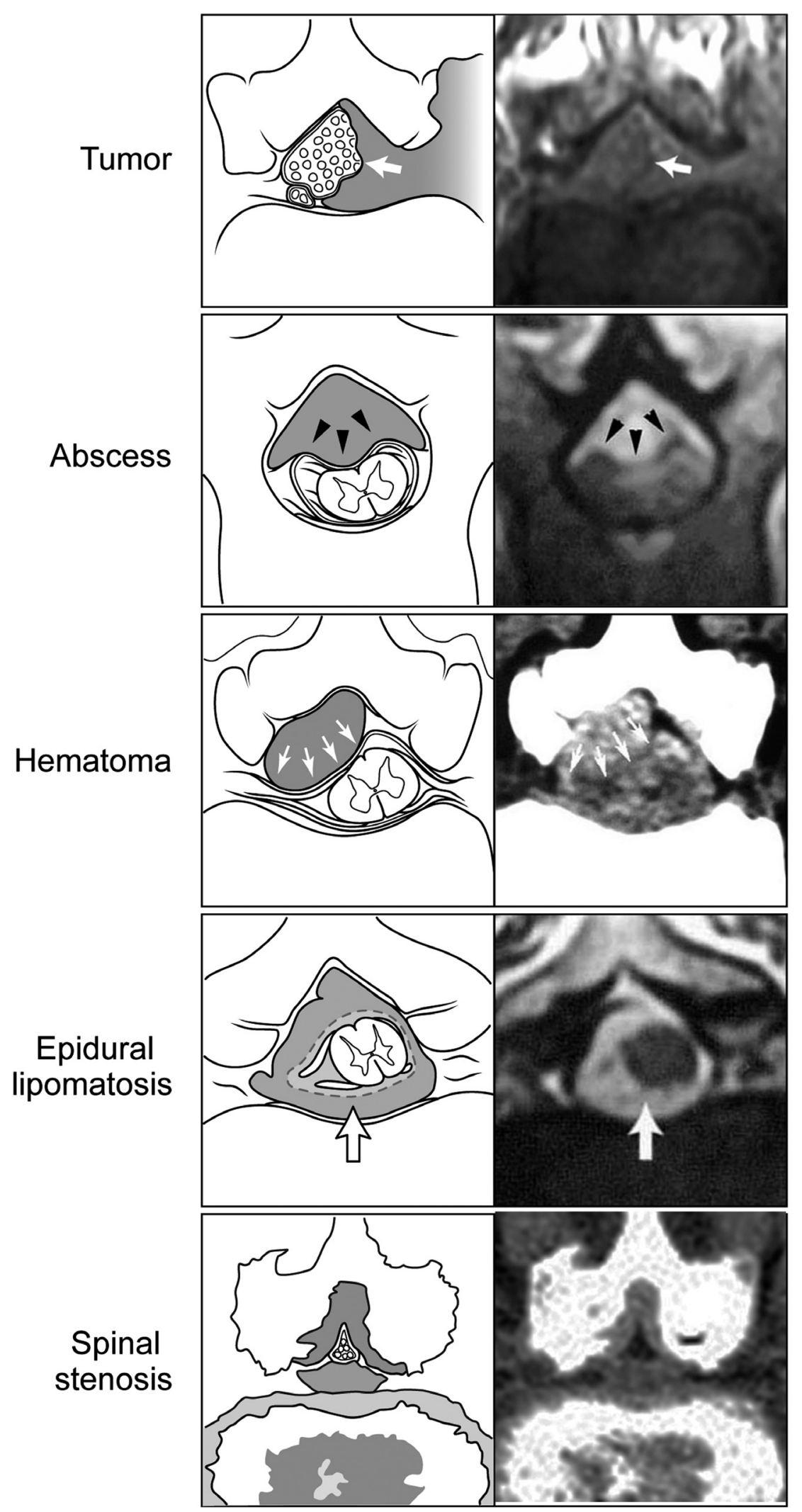

FIGURE 3. Extradural mass lesions. Note how various conditions can reduce spinal canal cross-sectional area and either directly compress the spinal cord or the cauda equina (arrows) or increase epidural space or CSF pressures through their mass effect. Illustration by Gary J. Nelson. Reproduced with permission from Neal and Rathmell, Complications in Regional Anesthesia and Pain Medicine. 


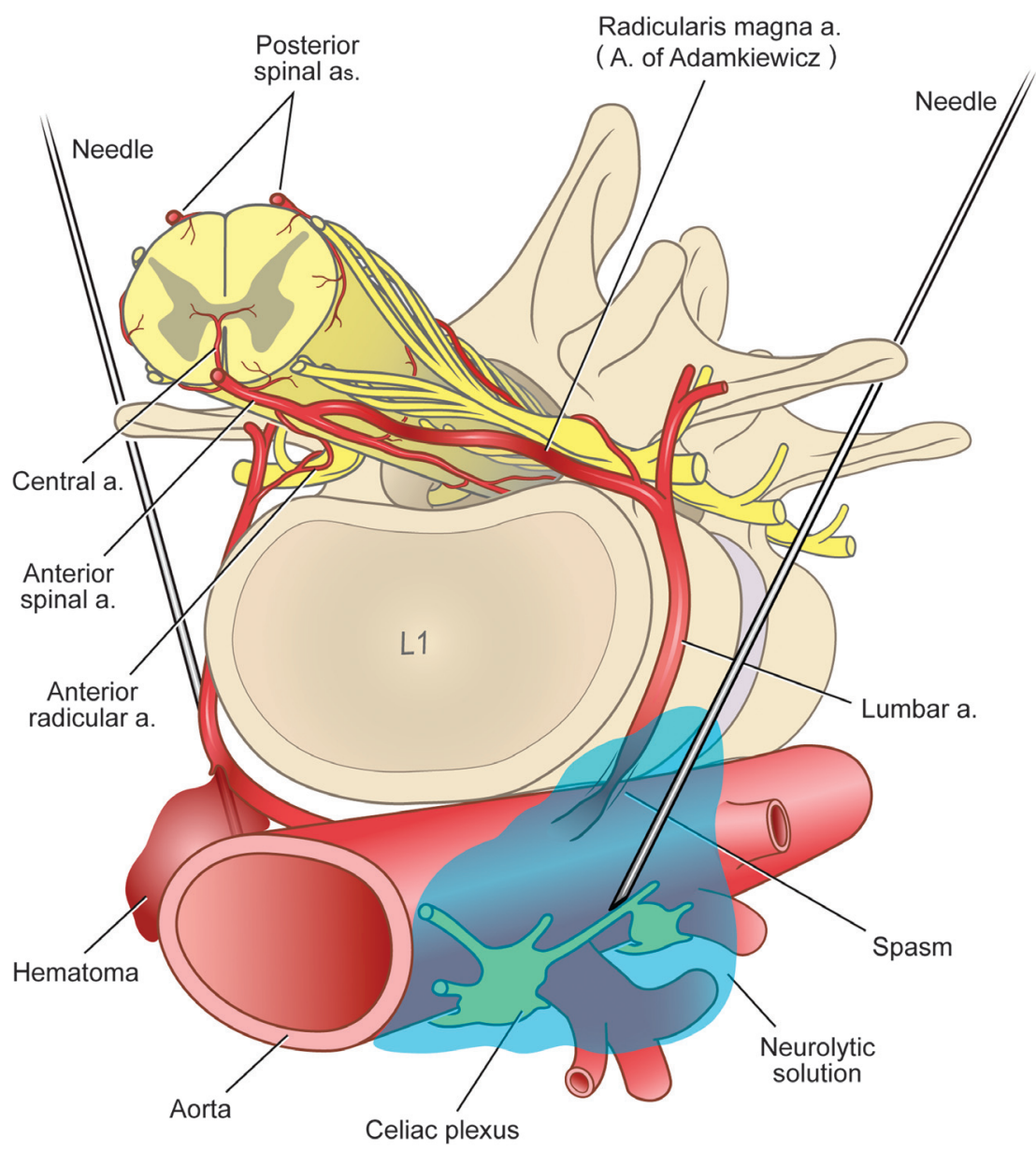

FIGURE 4. Proposed mechanisms of direct injury to reinforcing arteries supplying the spinal cord. On the left, a needle can potentially disrupt a segmental artery or precipitate a hematoma. On the right, needle irritation or injected phenol or alcohol (as used in neuroablation procedures) can cause vasospasm. These proposed mechanisms have not been proven in humans. Illustration by Gary J. Nelson. Reproduced with permission from Neal and Rathmell, Complications in Regional Anesthesia and Pain Medicine. ${ }^{32}$

the observed injury results from underlying spinal canal pathology, disease progression, surgical factors, patient positioning, or a combination thereof.

The advisory panel therefore acknowledges growing evidence of an association between spinal stenosis or other spinal canal pathology and a higher incidence of complications after neuraxial blockade. ${ }^{12,13,41,44}$ However, causation cannot be established definitively. To this point, the panel also acknowledges that a multitude of neuraxial regional anesthetics and interventional pain medicine procedures are performed daily on patients with varying degrees of spinal stenosis. In some of these cases, spinal stenosis has been diagnosed and may indeed be the indication for intervention. Furthermore, spinal stenosis can contribute to neurologic injury from surgery or positioning even in the absence of neuraxial anesthetic techniques. ${ }^{45,46}$ Based on details gleaned from the limited literature on this topic and in accordance with the double-crush theory, ${ }^{47}$ we believe it reasonable to speculate that patients with moderate to severe spinal stenosis might be more vulnerable to injury if there are coexisting conditions such as neuraxial surgery, preexisting neurologic disease, mucopolysaccharidosis, ${ }^{48}$ nonneutral patient positioning, or conditions known or unknown that compete for limited crosssectional area within the spinal canal. Although the preponderance of spinal stenosis has been associated with epidural and combined spinal-epidural techniques, ${ }^{12}$ association with spinal anesthesia has also been reported. ${ }^{35,44}$ As noted previously, the presence of spinal stenosis may be unknown to the clinician and the patient. However, those patients who report neurogenic claudication with symptoms that progress with ambulation are likely to have severe stenosis, even if not formally diagnosed. Recommendations for spinal stenosis are found in Table 2.

\section{Blood Pressure Control During Neuraxial Anesthesia}

Spinal cord ischemia or infarction associated with neuraxial regional anesthesia is a decidedly rare event that may present as anterior spinal artery syndrome (ASAS), posterior spinal artery syndrome, watershed infarction, or an ill-defined injury consistent with critically reduced or absent SCBF. For perspective, only 10 of 821 medicolegal claims for neuraxial injury contained within the ASA Closed Claims database were alleged to have resulted from ASAS or variations of spinal cord ischemia. ${ }^{7}$ A study of longterm outcomes after acute spinal cord ischemia documented that only 1 of 54 patients had actually received a neuraxial anesthetic. ${ }^{49}$ This should not be surprising, as the highest risks for perioperative spinal cord infarction are associated with specific operations, for example, aortic, cardiac, thoracic, or spine surgeries. Even 


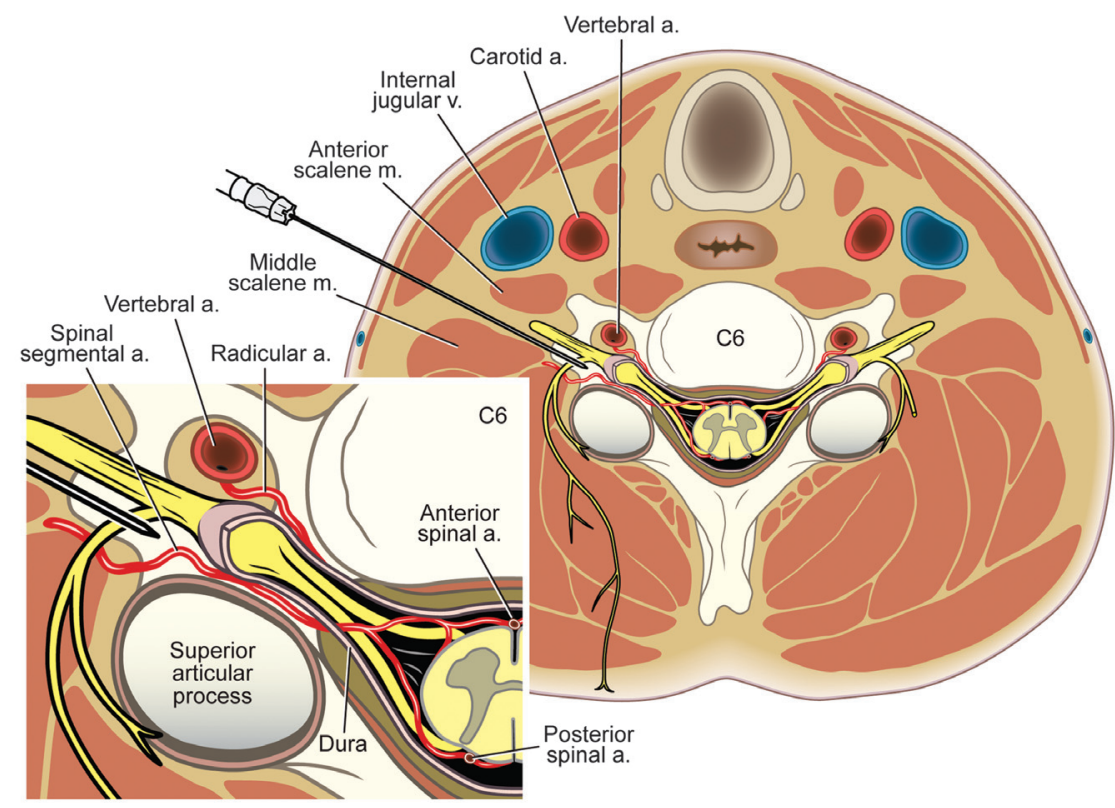

FIGURE 5. The transforaminal approach to the neuraxis may allow the needle to contact either the spinal nerve or the spinal artery. Illustration by Gary J. Nelson. Reproduced with permission from Neal and Rathmell, Complications in Regional Anesthesia and Pain Medicine. ${ }^{32}$

though autoregulation of SCBF mirrors that of cerebral blood flow $^{50}$ (Fig. 6), spinal stroke is apparently much less frequent than the estimated $0.1 \%$ incidence of perioperative cerebral stroke in patients undergoing noncardiac, nonneurologic surgery. ${ }^{51}$ Spinal cord ischemia and infarction are rarely reported even after clinical scenarios of prolonged low mean arterial pressure (MAP), such as during cardiopulmonary bypass or induced hypotension to a MAP of $60 \mathrm{~mm} \mathrm{Hg}$ or less. ${ }^{52-55}$ While it is relatively rare for survivors of cardiac arrest to develop spinal cord ischemic injury, $46 \%$ of those who died of cardiac arrest or a severe hypotensive episode manifested ischemic spinal cord myelopathy at autopsy. ${ }^{56}$ Despite the expectation that ischemic myelopathy would be most prevalent within the thoracic spinal cord watershed areas (because the thoracic spinal cord classically is supplied by fewer medullary arteries than either the cervical or lumbosacral spinal cord), $95 \%$ of cases in the previously noted postmortem study involved

TABLE 2. Recommendations: Patients With Spinal Stenosis

These recommendations are intended to encourage optimal patient care, but cannot ensure the avoidance of adverse outcomes. As with any practice advisory recommendation, these are subject to revision as knowledge advances regarding specific complications.

- Spinal stenosis represents a continuum of spinal canal encroachment by hypertrophied ligamentum flavum, bony overgrowth, and/or degenerative changes such as from osteoporosis or herniated nucleus pulposus. Patients with spinal canal pathology (eg, spinal stenosis, lumbar disk disease) may have clinical or subclinical evidence of a preexisting neurologic deficit due to neural compromise from the disease state. However, even moderately severe spinal stenosis is not always symptomatic; many patients (or their healthcare providers) are unaware that they have the condition. (Class I)

-When neuraxial anesthesia is complicated by the development of mass lesions within the spinal canal (eg, hematoma or abscess), resultant postoperative neurologic complications may be more likely or more severe in patients with spinal stenosis or other obstructive spinal canal pathology, including changes brought on by patient positioning. (Class I)

- In patients with known severe spinal stenosis or symptoms suggestive thereof, we recommend that risk-to-benefit analysis be considered prior to performance of neuraxial anesthesia because of the association of spinal stenosis with neurologic complications in the setting of neuraxial blockade. If neuraxial blockade is performed, we recommend heightened perioperative vigilance for symptoms suggestive of neural compromise. (Class II)

- There is no firm linkage to injury if spinal stenosis is at a site distant from the level of neuraxial block placement. (Class III)

- If neuraxial anesthesia is planned, the practitioner may consider reducing the total mass (volume $\times$ concentration) of local anesthetic in an effort to reduce segmental spread and local anesthetic neurotoxicity (which is related to concentration) and/or facilitate neurologic assessment by earlier block resolution. While we are unaware of routinely administered volumes of local anesthetic being associated with injury in patients with spinal stenosis, reports have postulated linkage between high volumes and neuraxial injury in the setting of other mass lesions such as epidural lipomatosis. (Class III)

- The literature has established an association between spinal stenosis and injury after neuraxial blockade, most often affecting patients in whom the diagnosis of spinal stenosis was made during workup for the injury. There is no clear evidence that spinal stenosis per se caused these injuries. (Class II)

- Currently, it is unclear whether the development of new or worsening neurologic symptoms after neuraxial anesthesia or analgesia is due to surgical factors, the anesthetic technique, the natural progression of spinal pathology, or a combination of these factors. (Class II)

Copyright @ 2015 American Society of Regional Anesthesia and Pain Medicine. Unauthorized reproduction of this article is prohibited. 


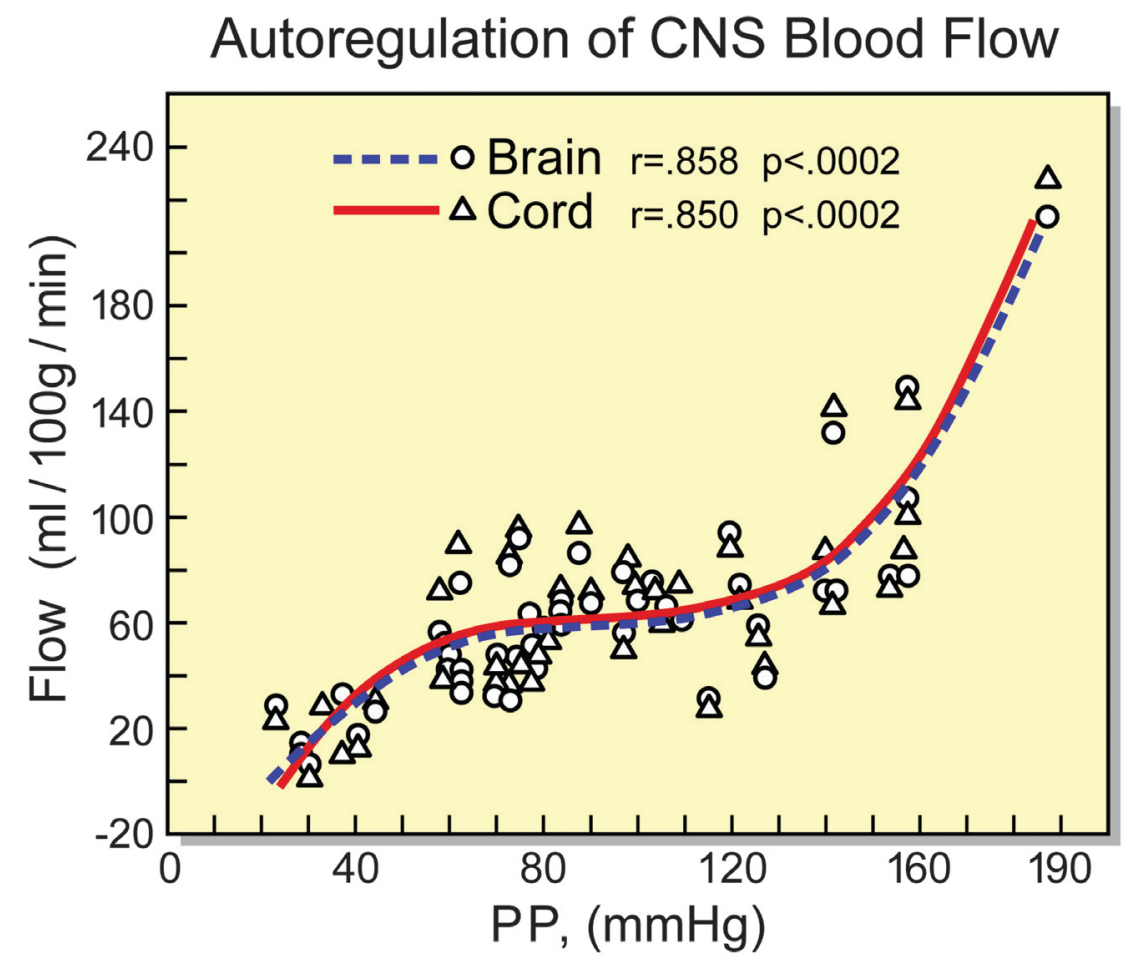

FIGURE 6. The autoregulation of SCBF (red) mirrors that of the brain (blue dashed line). Illustration by Gary J. Nelson. Modified from Hickey et $\mathrm{al}^{50}$ and reproduced with permission from Neal and Rathmell, Complications in Regional Anesthesia and Pain Medicine. ${ }^{32}$

the lumbosacral spinal cord, ${ }^{56}$ whereas nearly $50 \%$ of cases reported in a neuroradiologic study occurred at the cervical level. ${ }^{57}$

Although local anesthetics and especially adjuvants are often implicated as contributory to spinal cord ischemia, our 2008 advisory ${ }^{2}$ summarized that - inherent to an anesthetized spinal cordneither class of compounds reduces SCBF out of proportion to metabolic demand. ${ }^{58-61}$ Conversely, reduction in $\mathrm{CMRO}_{2}$ out of proportion to blood flow does not reliably predict cerebral protection, ${ }^{62}$ and it presumably has the same relationship in the spinal cord. Thus, neither local anesthetics nor adjuvants would be expected to influence cord injury based on an uncoupling of SCBF and metabolic rate, regardless of the direction of that uncoupling, in part because the magnitude of the uncoupling would be small. Vasoactive drugs such as epinephrine and phenylephrine do not adversely affect SCBF, whether delivered as an intrathecal adjuvant or in clinically appropriate intravenous doses. ${ }^{61,63,64}$

\section{The Argument for Avoiding Significant Hypotension During Neuraxial Anesthesia}

This advisory expands previous recommendations regarding blood pressure control during neuraxial anesthetics. These modifications are predicated by 2 developments: (1) an evolving understanding of brain and spinal cord lower limit of autoregulation (LLA) and (2) a growing body of literature and medicolegal experience that suggests the existence of an extremely rare subset of patients (including young patients with no increased cerebrovascular risk) who suffered spinal cord ischemia or infarction in clinical settings wherein the only or most likely abnormality was an extended period of marginally low blood pressure. ${ }^{65-67}$

With regard to our evolving understanding of CNS LLA, previous animal studies suggested that SCBF is autoregulated within a MAP range of 50 to $60 \mathrm{~mm} \mathrm{Hg}$ to 120 to $135 \mathrm{~mm} \mathrm{Hg}$, assuming (1) an intact blood-spinal cord barrier ${ }^{50,68}$ and (2) the
LLA for the spinal cord behaves in a similar manner as the LLA of the brain. In recent years, Drummond et $\mathrm{al}^{66,67}$ and others $^{61,69,70}$ have challenged the previously accepted dictum of MAP $50 \mathrm{~mm} \mathrm{Hg}$ representing a relevant and consistent cerebral LLA in humans and have instead presented evidence that cerebral LLA varies widely among individuals and is likely closer to 60 to $65 \mathrm{~mm} \mathrm{Hg}$ in normotensive, unanesthetized adults. These experts remind us that CNS blood flow does not stop upon reaching the LLA but that there is a range between baseline MAP, the LLA, and the blood pressure below which irreversible cell damage occurs. The limits of this "physiologic reserve" (between the LLA and the pressure at which cells manifest injury) are unknown but are speculated to be $30 \%$ to $40 \%$ below baseline MAP. ${ }^{67,71,72}$ Whereas physiologic reserve probably affords some degree of spinal cord protection against low-flow states, such protection is likely mitigated by the presence of vascular stenosis, embolic phenomena, erythrocyte sludging (eg, sickle cell disease), or when abnormal vascular anatomy impairs normal blood flow, as has been described in cases of focal cerebral ischemia. ${ }^{73}$ This last phenomenon is likely to exist with spinal vasculature anomalies as well.

Clinical support for these concepts can be gleaned from both animal and human studies. The bulk of these studies involve cerebral blood flow rather than SCBF, but the parallel autoregulatory curves of both systems argue that extrapolation from one to the other is reasonable ${ }^{50}$ (Fig. 6). For example, in a clinical study that precisely measured cerebral LLA in patients undergoing cardiopulmonary bypass, the mean LLA was a MAP of $66 \mathrm{~mm} \mathrm{Hg}$ and ranged widely (95\% prediction interval, 43-90 $\mathrm{mm} \mathrm{Hg}$ ). In this study, preoperative MAP was not predictive of brain LLA, and only preoperative systolic blood pressures in excess of $160 \mathrm{~mm} \mathrm{Hg}$ correlated with a higher LLA. ${ }^{69}$ Another study noted that patients undergoing shoulder surgery frequently reached the cerebral LLA at a MAP of 65 to $70 \mathrm{~mm} \mathrm{Hg}$, especially when in 
the beach-chair (ie, semisitting) position (BCP). ${ }^{70}$ Similarly, in a study of dogs administered spinal anesthesia and then acutely hemorrhaged, SCBF began to decrease at a MAP of $66 \mathrm{~mm} \mathrm{Hg.}{ }^{74}$

Circumstantial support for the injurious role of hypotension can also be found in spinal deformity surgery, wherein the correction of hypotension has been reported to reverse electrophysiologic signs of spinal cord dysfunction. ${ }^{75}$

With regard to the duration of hypotension, a case-control study of 48,241 patients undergoing noncardiac, nonneurologic surgery reported that those patients whose MAP was $30 \%$ or greater below preoperative baseline had a significantly higher risk of perioperative ischemic cerebral stroke, which also correlated with the duration of hypotension. ${ }^{71}$ Moreover, it is possible that prolonged periods of lesser degrees of hypotension (or, alternatively, local tissue hypoperfusion) may also be significant, as inferred from the observation that some patients with ASAS developed symptoms over time; that is, not all presented with sudden flaccid paralysis. ${ }^{49}$

In summary, this advisory's new admonition to avoid significant hypotension (especially of prolonged duration) during neuraxial blockade is based on evolving evidence that the LLA of cerebral blood flow and SCBF appears to be higher than previously accepted. Furthermore, there is an increasing awareness that the range of cerebral and spinal cord LLA is wide in humans, and that at least a subset of patients with otherwise "low normal" MAPs can manifest signs of spinal cord ischemia or sustain injury. Large clinical studies directly linking low blood pressure to spinal cord injury are lacking. Instead, we have only association gleaned from case reports or extrapolated from limited human studies of surrogate end points, for example, measuring cerebral LLA during cardiopulmonary bypass or reversal of electrophysiologic deficits during spinal surgery consequent to correction of low blood pressure.

\section{Perspective on Blood Pressure Control During Neuraxial Anesthesia}

Despite concerns over prolonged, significant hypotension as a risk factor for spinal cord ischemic injury, the rarity and nature of such injury make it impossible to assume cause and effect. In most reported cases, the absence of clinical details or the existence of other potentially confounding etiologies precludes cause and effect. ${ }^{76}$ Multiple studies point to the relative safety of prolonged hypotension in humans during general and/or regional anesthesia. For instance, clinical studies of prostaglandin-induced hypotension during spinal surgery note the absence of cord injury during prolonged periods of $60 \mathrm{~mm} \mathrm{Hg} \mathrm{MAP.}{ }^{55}$ Yet, in a different model, devastating brain or cervical spinal cord injuries and death have been speculated to be causally related to hypotension in otherwise healthy patients undergoing shoulder surgery in the BCP. ${ }^{65}$ These injuries are extremely rare and arguably fall within the expected rate of perioperative cerebral stroke. ${ }^{51}$ Three series that total more than 9300 patients operated on in the BCP reported no cerebral or cervical spinal cord ischemic injuries despite approximately half of patients in both studies experiencing a hypotensive episode (defined as $30 \%$ to $40 \%$ reduction of baseline MAP, systolic pressure $<90 \mathrm{~mm} \mathrm{Hg}$, decreased cerebral oxygen saturation, and/or MAP $<66 \mathrm{~mm} \mathrm{Hg}$ ). The duration of hypotension experienced by these patients was relatively limited (only $5 \%-7 \%$ of operative time [15-18 minutes]). ${ }^{77-79}$ Laflam et al $^{70}$ reported in a prospective study that patients operated on in the BCP often experience diminished autoregulation over a wide range of MAP ( $70 \mathrm{~mm} \mathrm{Hg}$; interquartile range, $55-80 \mathrm{~mm} \mathrm{Hg}$ ), yet did not exhibit evidence of brain injury. Overall, these results can be interpreted as supporting the concept of a physiologic reserve that protects the vast majority of patients from injury, even when limited periods of low MAP occur at the brain or cervical spinal cord level while in the BCP.

Perhaps more apropos to patients undergoing neuraxial regional anesthesia, Sharrock and colleagues ${ }^{80}$ reported decades of experience with hypotensive epidural anesthesia for total hip arthroplasty, in which their goals were to reduce blood loss and to improve acetabular prosthetic component adherence. Their work can be summarized as induced hypotension to a MAP of 45 to $55 \mathrm{~mm} \mathrm{Hg}$ that was typically maintained for 30 to 120 minutes, but occasionally longer. Sharrock et $\mathrm{al}^{80}$ reported that this regimen did not adversely affect renal function, cognitive function, ${ }^{81}$ or cardiac function, even in elderly patients with preexisting ischemic cardiac disease and/or hypertension. ${ }^{82}$ Of critical importance is understanding that Sharrock and colleagues' intraoperative routine involved much more than using dense epidural anesthesia to induce hypotension. Their regimen included meticulous attention to details such as maintaining neutral spine position, central venous pressure, and cardiac output. With regard to cardiac function, their use of low-dose epinephrine infusion (1-4 $\mu \mathrm{g} / \mathrm{min})$ preserved central venous pressure, heart rate, cardiac stroke volume, cardiac output, and cardiac index. They reported that epinephrine is superior for maintaining these vital parameters, rather than phenylephrine, which adversely affected heart rate and cardiac index. ${ }^{83,84}$ Thus, we can infer that, despite prolonged low MAP, Sharrock and colleagues' clinical regimen promoted forward blood flow and avoided excessive cardiac afterload.

To place our argument for increased awareness of blood pressures during neuraxial anesthesia into perspective, the rate of cerebral and spinal cord injury during all surgeries is remarkably low, even under potentially "physiologically stressful conditions" such as the BCP and induced hypotension. The vast majority of patients appear to tolerate limited periods of marginal hypotension. We nevertheless posit that an extremely small subset of patients either lack a physiologic reserve or have a higher set point for their individual LLA, which we speculate increases their susceptibility to a spinal cord ischemic event. Furthermore, positioning in other than the neutral supine position may enhance the vulnerability of these patients to new-onset spinal cord ischemia, whether the positioning alterations are the result of preincision surgical positioning or alterations in local or regional anatomic relationships that result from surgical retraction.

One of the arguments to allow blood pressure to decline, or even to pharmacologically reduce blood pressure to below the patient's baseline values, is a desire to lessen blood loss in the surgical field. The literature is conflicting as to whether this approach results in clinically meaningful reductions in blood loss, especially that requiring blood transfusion. ${ }^{85}$ We advise that the relative benefits of general anesthesia versus neuraxial anesthesia be carefully weighed for those patients who may benefit from induced hypotension and that the potential risks of prolonged hypotension be considered for each individual patient.

\section{Recommendations}

Recommendations for blood pressure control during neuraxial regional anesthesia are summarized in Table 3. Our previous advisory emphasized the rarity of blood pressure-related CNS injury, but noted that if spinal cord ischemia or infarction occurs the chance for recovery is extremely poor. ${ }^{86}$ This current advisory acknowledges scientific and medicolegal reports of ischemic spinal cord injury in patients without obvious risk factors other than a prolonged period of frank or borderline hypotension. Although lower blood pressures are apparently safe in the vast majority of patients, there appears to exist an unpredictable 
TABLE 3. Recommendations: Blood Pressure Control During Neuraxial Anesthesia

These recommendations are intended to encourage optimal patient care, but cannot ensure the avoidance of adverse outcomes. As with any practice advisory recommendation, these are subject to revision as knowledge advances regarding specific complications.

- Local anesthetics, adjuvants, and their combination have variable effects on SCBF. Reduction of SCBF in the presence of local anesthetics and adjuvants typically mirrors reduction in metabolic demand secondary to spinal cord anesthesia. There is no evidence that either intravenous or intrathecal epinephrine or phenylephrine adversely affects SCBF. (Class I)

- Our understanding of the lower limits of autoregulation of SCBF has evolved recently, based on inferences gained from cerebral LLA studies. Rather than the previously accepted cerebral LLA at a MAP of $50 \mathrm{~mm} \mathrm{Hg}$ in humans, many experts now believe the cerebral LLA in unanesthetized adults is 60 to $65-\mathrm{mm} \mathrm{Hg}$ MAP. There is a wide variability of LLA among subjects. Preexisting hypertension appears to be a poor predictor of LLA except at the extremes of hypertension, eg, systolic pressure $>160 \mathrm{~mm} \mathrm{Hg}$. (Class II)

- Case reports attest to an extremely small subset of patients who have sustained cerebral or spinal ischemia associated with periods of severe or prolonged low blood pressure. These rare events stand in stark contrast to the common perioperative occurrence of relative hypotension that does not result in spinal cord ischemia. Presumably, injury does not manifest in these patients because of a physiologic reserve that exists between the LLA and blood pressure thresholds below which neurologic injury occurs. (Class III)

- When the LLA of SCBF is approached, specific patient conditions may increase the risk of injury. Such conditions include reduced blood oxygen-carrying capacity, impairment of SCBF from obstructing anatomic lesions, and/or increased spinal cord CSF pressure. (Class I)

- In the absence of compelling reasons to manage a patient otherwise, we recommend that blood pressures during neuraxial anesthesia be maintained in normal ranges or at least within 20\%-30\% of baseline MAP. When MAP goes below these parameters, we recommend that it not be allowed to persist at those levels. While these recommended parameters are arbitrary, they are inferred based on large population studies that have linked both degree and duration of hypotension to perioperative cerebral, renal, or myocardial injury. (Class II)

-When neuraxial anesthesia or analgesia is followed by unexpectedly prolonged sensory or motor blockade, recrudescence of weakness or sensory changes after initial block resolution, or neural blockade outside the expected distribution of the intended procedure, the anesthesiologist must rule out reversible causes in an expedient manner. At the physician's judgment, this may entail reduction or discontinuation of local anesthetic infusion and reexamination of the patient within an hour or immediate neuroimaging to exclude a compressive process (hematoma or abscess). If imaging is ordered, magnetic resonance imaging is preferable to CT, but the diagnosis should not be delayed if only CT is available. However, if CT rules out a compressive lesion, subsequent magnetic resonance imaging will be necessary if spinal cord ischemia is suspected. (Class I)

- If imaging rules out an operable mass lesion and spinal cord ischemia is suspected, practitioners should ensure at least normal blood pressure or consider inducing high-normal-range blood pressure. The efficacy of CSF pressure modulation via lumbar drains in anesthesia/interventional pain medicine-related spinal cord ischemia is unknown, but the technique is widely used to treat surgery-related spinal ischemia and appears safe in the setting of ischemic spinal cord injury. (Class III)

- The role of corticosteroids in anesthesia-related injuries is unknown. Corticosteroids may have a beneficial effect after direct spinal cord trauma resulting from interventional procedures. However, the potential benefits for these patients should be balanced against the associated risk of corticosteroid-associated hyperglycemia; ie, hyperglycemia worsens brain (and presumably spinal cord) ischemic injury. We do not recommend the use of corticosteroids for ischemic spinal cord injury. Definitive diagnosis and treatment are best determined in consultation with neurology or neurosurgery colleagues. (Class III)

subset of patients who are at risk of spinal cord injury when low blood pressure is associated with spinal stenosis, ${ }^{13,66,87}$ anemia (reduced oxygen-carrying capacity), ${ }^{66}$ hypocapnia, raised intrathoracic pressure (eg, during mechanical ventilation in lung-injured patients), extremes of patient position, chronic hypertension, unrecognized vascular abnormalities, variation in the LLA, or as yet undiscovered conditions. The panel therefore recommends that anesthesiologists strive to maintain blood pressure within $20 \%$ to $30 \%$ of baseline and that persistent hypotension be treated, especially in the absence of neuromonitoring that could identify any new-onset insults. This may be especially true in pediatric patients, particularly infants, who normally have lower baseline MAPs than adults and who manifest higher epidural space pressures upon injection of fluid. ${ }^{26,30}$

\section{Diagnosis and Treatment}

If signs and symptoms of spinal cord ischemia occur, rapid intervention is mandatory to rule out potentially correctable causes such as spinal hematoma or abscess. Based on clinical presentation, the anesthesiologist may elect to reduce or stop the local anesthetic infusion and reevaluate the patient within an hour or alternatively proceed directly to imaging to rule-out a treatable intraspinal mass. For diagnosing ischemia, magnetic resonance imaging scan may be normal within the first few hours of symptoms, but hours to days later, it may reveal focal cord swelling or hyperintensities on T2-weighted images. ${ }^{57,88,89}$
If ischemia is suspected, normalizing or inducing highnormal-range blood pressure and/or CSF drainage have been recommended, but their effectiveness is not fully supported by the literature. ${ }^{51}$ While limited data support the role of CSF lumbar drainage in aortic aneurysm surgery ${ }^{90}$ and its use is generally safe, ${ }^{91}$ there are no data specific to its efficacy in anesthesiaor pain medicine procedure-related injuries.

Likewise, there are no data specific to the role of corticosteroids in anesthetic or pain medicine intervention-associated neuraxial injury; we are thus left to extrapolate the literature of brain and spinal cord traumatic injury, and cerebrovascular ischemia, to anesthesia-related injuries. Although controversial, ${ }^{92}$ corticosteroid drugs have Cochrane Review-level evidence for improving outcome after acute traumatic spinal cord injury. ${ }^{93}$ Conversely, corticosteroids have been shown not advantageous for acute head injury ${ }^{94}$ or cerebral stroke. ${ }^{95}$ Furthermore, a considerable and growing body of literature reports that corticosteroids can be directly injurious (ie, glucose independent) to hypoxic/ischemic animal spinal cords, ${ }^{96}$ neurotoxic to human brains after traumatic brain injury ${ }^{97}$ and secondarily neurotoxic as a result of increases in blood glucose concentrations. ${ }^{92,98,99}$ While fully acknowledging this conflicting literature and the absence of studies directly related to anesthesia-related injuries, the advisory panel suggests that administration of corticosteroids may be beneficial in cases of direct spinal cord trauma related to interventional procedures. However, because steroid administration has been shown in animals and humans to worsen outcome in the setting of neurologic 
ischemia, we recommend that corticosteroids not be used in suspected cases of spinal cord ischemia or infarction. In either case, maintenance of normoglycemia (such as through administration of insulin in a previously hyperglycemic patient) is advised. We recommend neurologic consultation to help evaluate the nature and mechanisms of any insults and to coordinate possible treatments.

\section{Establishing "Baseline Blood Pressure"}

There are no reliable historical or diagnostic criteria that identify patients susceptible to spinal ischemia in the setting of neuraxial regional anesthesia. Furthermore, most studies have failed to link baseline hypertension to an increased risk of anesthesia-associated ischemic cerebral or spinal cord injury. Just as there are no firm guidelines for what constitutes the SCBF LLA and for what duration blood pressures less than the LLA become injurious, the determination of "baseline blood pressure" in an individual patient is difficult. A recent study ${ }^{100}$ observed that MAP of less than $55 \mathrm{~mm} \mathrm{Hg}$, particularly if lasting longer than 20 minutes, predicted a higher rate of adverse cardiac and renal (not cerebral) outcomes in 33,000 noncardiac surgery patients. Nevertheless, we agree with the editorial opinion $^{101}$ that such results cannot be extrapolated to an individual patient. Moreover, recent studies have discovered that average preoperative blood pressures are not predictive of the LLA. ${ }^{69,70}$

Despite the unclear relationship of baseline blood pressure to LLA, anesthesiologists nevertheless often wish to ascertain a patient's baseline MAP. A study that sought to correlate perioperative blood pressures to true baseline found that a normal blood pressure obtained on arrival in the operating room closely approximated that patient's true baseline. However, if the first operating room blood pressure was hypertensive, it was less likely to represent baseline. Instead, an average of ambulatory blood pressures over the past 7 months or a preoperative blood pressure obtained 1 to 30 days prior to surgery more accurately reflected that patient's baseline. ${ }^{102}$

\section{Transforaminal Pain Medicine Procedures}

We have previously detailed the emerging evidence linking use of particulate steroids with catastrophic neural injuries when administered for treatment of painful conditions via the transforaminal route. Reported complications include spinal cord infarction, cortical blindness, paralysis, and death. ${ }^{103-105}$ As noted in our 2008 advisory, "the presumed mechanism of these complications involves unintentional needle entry into a small artery that traverses the intervertebral foramen to join the arterial supply to the spinal cord or posterior circulation of the brain. This can occur at various levels, including the vertebral artery anterior to the cervical intervertebral foramina or the spinal medullary or radicular arteries within the foramina at variable levels within the cervical, ${ }^{106,107}$ thoracic, lumbar, and sacral portions of the spine (Fig. 5). Subsequent injection of particulate steroid preparations can result in occlusion of the distal arterioles within the spinal cord or brain and lead to infarction. ${ }^{104}$ In the interim since the 2008 practice advisory, a collaboration between the US Food and Drug Administration's Safe Use Initiative and a group with representation from numerous specialties with interest and expertise in treating spinal disorders led to the publication of an article that reviews the existing evidence regarding transforaminal injections and catastrophic neural injuries and puts forward a series of expert opinions meant to improve safety. ${ }^{108}$ We will henceforth summarize the newer evidence that has emerged regarding transformational injections.
Additional evidence has emerged that direct traumatic injury to the spinal cord can and rarely does occur during cervical transforaminal techniques, ${ }^{109,110}$ but the cardinal neurologic complications of this procedure are infarctions of the spinal cord, brainstem, cerebrum, or cerebellum. ${ }^{111-121}$ A review of closed claims identified 9 instances of spinal cord infarction, although the overlap with the published case reports could not be determined. ${ }^{110}$ The literature reporting paraplegia following lumbar transforaminal injections has also grown. ${ }^{122-126}$ Particulate steroids were used in all cases, and the suspected mechanism of injury was either injection of steroids into a radiculomedullary artery or spasm of an artery when disturbed by a needle.

The role of particulate steroids as causative agents in producing neurologic injury after intra-arterial injection has been further clarified. In vitro studies note that methylprednisolone has the largest particles, betamethasone the smallest, and dexamethasone has no particulate matter. ${ }^{127}$ Animal studies have clearly demonstrated that injection of particulate methylprednisolone into the vertebral artery or internal carotid artery can lead to strokes similar to those seen in published human case reports. ${ }^{128,129}$ Such injuries did not occur after the injection of the nonparticulate steroid dexamethasone. The amassing evidence strongly suggests that intraarterial injection of particulate steroids is a mechanism underlying some spinal or cerebrovascular complications of cervical transforaminal injections. In virtually all case reports of infarction following cervical transforaminal injection of steroids, particulate steroids were used. There is now evidence from small studies that demonstrates the effectiveness of dexamethasone is not significantly less than that of particulate steroids. ${ }^{130,131}$ Further studies comparing particulate, nonparticulate, and other injectates are much needed, because many practitioners still strongly believe that particulate steroids are associated with more profound pain relief that is of longer duration than that provided by the nonparticulate steroid dexamethasone.

Our 2008 recommendations regarding transforaminal injections ${ }^{6}$ have been modified to align with the 2015 US Food and Drug Administration's Safe Use Initiative. ${ }^{108}$ These revised recommendations are presented in Table 4.

TABLE 4. Recommendations: Transforaminal Injection Techniques

These recommendations are intended to encourage optimal patient care, but cannot ensure the avoidance of adverse outcomes. As with any practice advisory recommendation, these are subject to revision as knowledge advances regarding specific complications.

- To avoid direct injection into critical structures, final position of an immobile needle during transforaminal injection should be confirmed by injecting contrast medium under real-time fluoroscopy and/or digital subtraction imaging, using an anteroposterior view, before injecting any substance that may be hazardous to the patient. (Class III)

- Because of the significantly higher risk of catastrophic neurologic injuries associated with cervical transforaminal injections, particulate steroids should not be used in therapeutic cervical transforaminal injections. (Class III)

- Although the risk of neurologic injury is markedly lower when performed at lumbar levels, a nonparticulate steroid (eg, dexamethasone) should be used for the initial injection in lumbar transforaminal epidural injections. (Class III)

- Particulate steroids can be considered under some circumstances for lumbar transforaminal injections, eg, after failure to respond to treatment with a nonparticulate steroid. (Class III) 


\section{Cauda Equina Syndrome, Local Anesthetic Neurotoxicity, and Arachnoiditis}

Our previous article emphasized the unique anatomic and physiologic attributes of the cauda equina that might make it particularly vulnerable to local anesthetic-induced neurotoxicity. ${ }^{2}$ These attributes include neural elements that are not fully protected by myelin, have a large surface-to-volume ratio, may experience reduced drug clearance because of limited vascular supply, ${ }^{132}$ and may have limited CSF dilutional capacity when local anesthetic is injected into a dural root sleeve ${ }^{133}$ (Fig. 7). This current practice advisory addresses 3 topics not fully explored in the first iteration: CES, transient neurologic symptoms (TNS) associated with 2-CP, and arachnoiditis. We have chosen to arbitrarily combine these topics because of a shared presumed mechanism of injury that involves neurotoxicity.

\section{Cauda Equina Syndrome}

Similar to emerging concerns regarding spinal canal mass lesion pathologies, CES has been associated with spinal stenosis. In Moen and colleagues ${ }^{12}$ study of 1.7 million neuraxial anesthetics, there were 32 cases of CES, 9 of which occurred in patients with previously undiagnosed spinal stenosis. In theory, a tight spinal canal, perhaps exacerbated by extreme surgical positions, might result in pressure-induced spinal cord ischemia or reduced vascular clearance, either of which might increase cauda equina susceptibility to local anesthetic neurotoxicity. Of the 18 cases of CES associated with spinal anesthesia, 8 patients received lidocaine 5\%,10 received bupivacaine, and 1 received a mixture of the 2 .

Of perhaps greater concern from Moen and colleagues, 12 study is that 23 of 32 cases were associated with nothing extraordinary in terms of spinal canal diameter, local anesthetic dosing, potential needle trauma, or abnormal postinjury imaging, all of which emphasize the unclear etiology of this syndrome. Although there are several known risk factors for the development of CES, we will offer 2 additional speculative mechanisms. With regard to known risk factors, data from the French surveillance studies ${ }^{134,135}$ and reports of CES associated with microcatheter continuous spinal anesthesia ${ }^{136}$ strongly suggest that CES can result from supernormal doses of intrathecal local anesthetics and/or maldistribution of local anesthetic spread within the caudad intrathecal sac. Based on a limited understanding of the mechanism of CES injury, we speculate that, in addition to supernormal dose

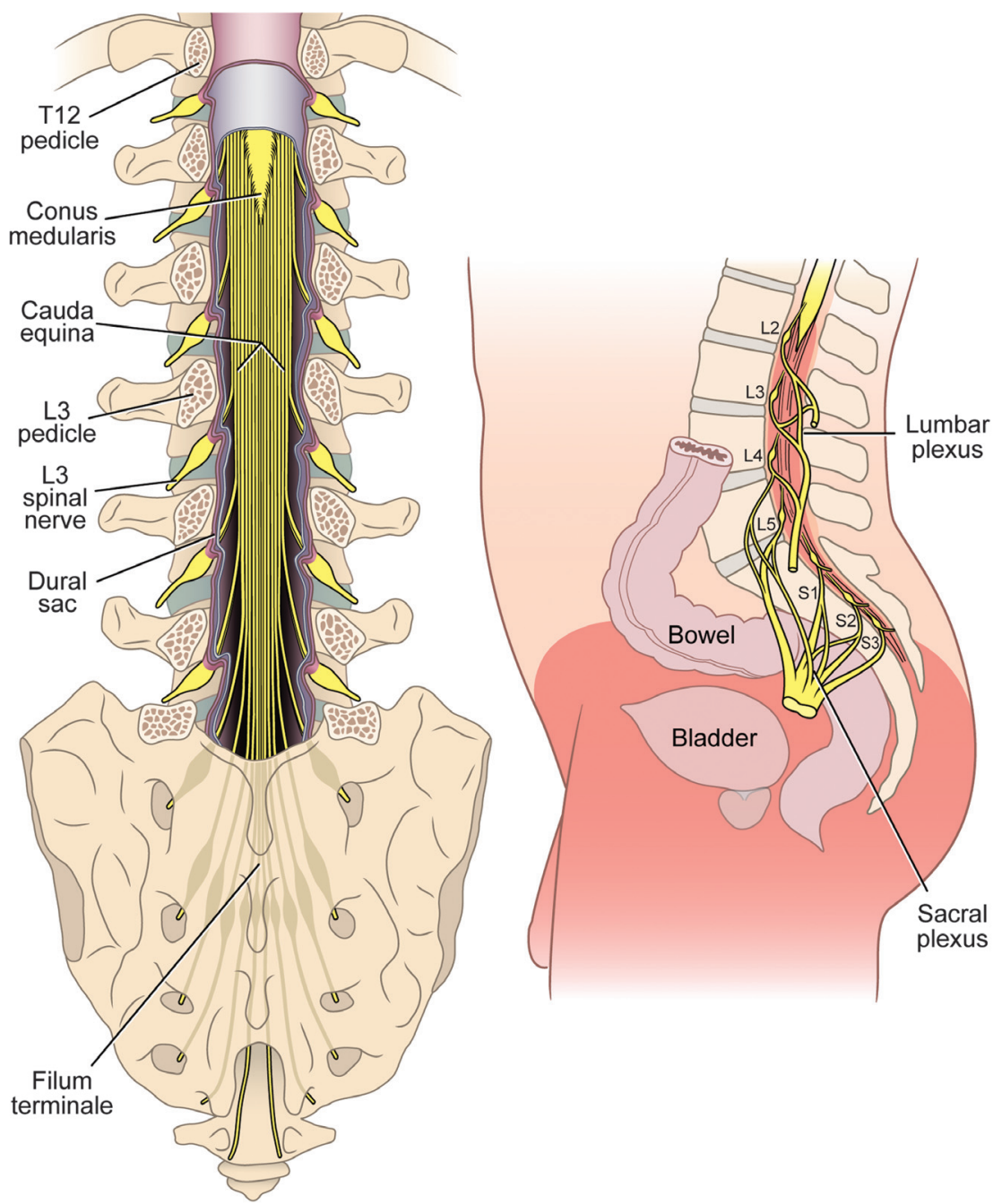

FIGURE 7. The cauda equina may be particularly prone to local anesthetic neurotoxicity because of the large surface area afforded by the long travel distance of nerve roots that have only partial or absent myelin covering. Illustration by Gary J. Nelson. Reproduced with permission from Neal and Rathmell, Complications in Regional Anesthesia and Pain Medicine. ${ }^{32}$ 
and maldistribution of local anesthetic, (1) an extremely small subset of humans may be predisposed to neurotoxicity from clinically appropriate doses of local anesthetic. Alternatively, we speculate that (2) abnormal neural inflammation may occur in response to exposure to local anesthetic, adjuvant, needle trauma, ${ }^{12,137}$ or other factors unrelated to the anesthetic. While the majority of cases of CES occur in patients with no known risk factors or no identified improper anesthetic technique, clinicians are advised to carefully weigh the risks to benefits of subarachnoid anesthesia in patients with known moderate to severe lumbar spinal stenosis and to avoid redosing failed, partial, or maldistributed spinal anesthetics (or at least not exceed the total recommended maximum dose). ${ }^{138}$

\section{Local Anesthetic Neurotoxicity}

Transient neurologic symptoms after spinal anesthesia were the subject of significant scientific inquiry nearly 2 decades ago. ${ }^{139}$ Experts continue to debate the etiology of TNS and whether it represents a forme fruste of neurotoxicity. At the time of our first advisory, several laboratory studies had examined for possible 2-CP-related neurotoxicity, ${ }^{140-142}$ but there was limited clinical research to confirm or refute whether 2-CP might indeed be neurotoxic in humans. ${ }^{143,144}$ Within the past few years, several reports have described the apparently safe use of low-dose (40-50 mg) spinal 2-CP in terms of TNS, ${ }^{145-147}$ albeit the patient numbers are too small to adequately judge overall safety for an event as rare as CES. Indeed, a study comparing 2-CP to lidocaine for ambulatory transurethral prostate resection described a case of incomplete CES (confirmed by positive nerve conduction study and electromyographic deficits) that resolved completely after several weeks in a subject who received $2-\mathrm{CP}{ }^{148}$ Intrathecal $2-\mathrm{CP}$ remains an off-label indication in the United States; however, in 2013, a $1 \%$ 2-CP solution was approved for intrathecal use in Europe. Based on the absence of appropriately powered studies for rare events, we cannot offer a recommendation with regard to intrathecal 2-CP and CES. However, we acknowledge a growing research literature that attests to acceptably low risk of TNS after low-dose intrathecal 2-CP.

\section{Arachnoiditis}

Arachnoiditis was not addressed in our previous advisory. This poorly understood entity describes diffuse inflammatory reaction of the 3 meningeal layers that manifests clinically in a spectrum from pain and disability to hydrocephalus and death. Historically, arachnoiditis has been associated with infection, trauma, intrathecal blood, contrast media, neuraxial hypertonic saline, ${ }^{149}$ and multiple back surgeries. ${ }^{150}$ Two potential etiologies are especially pertinent to the regional anesthesiologist and pain physician. While allergic, inflammatory, or idiosyncratic reactions to local anesthetics have been entertained as an etiologic factor for arachnoiditis, reasonably large studies suggest that if this association exists it is exceedingly rare. ${ }^{12,151-153}$ Attention has also been paid to the role of skin disinfectants. The latter concern stems from case reports ${ }^{154,155}$ of severe arachnoiditis after spinal or epidural anesthesia in which the "most likely mechanism" involved contamination by chlorhexidine. Many of these cases presented with remarkable similarity - headache or extremity burning immediately after injection of the local anesthetic, followed days later by evidence of increased intracranial pressure from hydrocephalus that required shunting, followed weeks later by progressive motor and sensory impairment to the point of paraplegia and chronic pain. This delay in major symptoms confounds identification of these cases by typical anesthesia surveillance mechanisms, but also argues for an idiosyncratic mechanism that might stem from an early, minor inflammatory reaction of the meninges in response to a drug, disinfectant, or other triggers.

The role of chlorhexidine/alcohol mixtures in the etiology of arachnoiditis is unclear and circumstantial. Numerous contemporary studies point to the clear superiority of chlorhexidine for skin asepsis as compared with povidone-iodine. This has resulted in the American Society of Regional Anesthesia and Pain Medicine, ${ }^{9}$ the ASA, ${ }^{156}$ the Centers for Disease Control and Prevention, and the Royal College of Anaesthetists ${ }^{152}$ recommending chlorhexidine as the skin disinfectant of choice. A retrospective cohort study of 12,465 spinal anesthetics in which $2 \%$ chlorhexidine gluconate in isopropyl alcohol was used for skin antisepsis did not find increased risk of any neuraxial complication over historical controls ( 57 cases lasting $<30$ days; $0.04 \%$; $95 \%$ confidence interval, $0.00 \%-0.08 \%) .{ }^{157}$ An in vitro study of human neuronal and rat Schwann cells found that chlorhexidine was no more cytotoxic than povidone-iodine at relevant clinical concentrations. Furthermore, the amount of dried antiseptic carried by a needle tip from skin-to-subarachnoid space was calculated to undergo a 1:145,000 dilution. ${ }^{158}$

Based on the superiority of chlorhexidine as an antiseptic and the extremely low likelihood that it would cause arachnoiditis under normal clinical conditions, the advisory panel continues to recommend it as the disinfectant of choice for neuraxial and peripheral nerve block techniques. Nevertheless, practitioners are advised to physically and temporally separate chlorhexidine from the block procedure itself. This implies allowing the solution to completely dry prior to needle placement (2-3 minutes). Steps should be taken to avoid chlorhexidine contamination of the block tray and/or drugs intended for intrathecal administration, as might occur from splashing or dripping the disinfectant, disposal of the applicator device near the block setup area, or pouring liquid chlorhexidine into receptacles where it could be mistaken for other drugs.

Recommendations regarding CES, local anesthetic neurotoxicity, and arachnoiditis are presented in Table 5.

TABLE 5. Recommendations: CES, Local Anesthetic Neurotoxicity, and Arachnoiditis

These recommendations are intended to encourage optimal patient care, but cannot ensure the avoidance of adverse outcomes. As with any practice advisory recommendation, these are subject to revision as knowledge advances regarding specific complications.

- Initial dosing or redosing of subarachnoid local anesthetic in excess of the maximum recommended dose may increase the risk of spinal cord or spinal nerve root neurotoxicity and should be avoided. In addition, maldistribution (usually sacral) of local anesthetic spread should be ruled out prior to redosing single-injection or continuous subarachnoid blocks. (Class I)

- The risk-to-benefit analysis of neuraxial techniques should be considered in patients known to have moderate to severe spinal stenosis, especially if within the vertebral territory of the intended injection. (Class II)

- The incidence of TNS after 40-50 mg intrathecal 2-CP appears to be remarkably low. The number of 2-CP spinal anesthetics reported in the literature is insufficient to determine the risk of CES or other manifestations of neurotoxicity. (Class III)

- Physically and temporally separate chlorhexidine use from block trays and instruments during neuraxial procedures. Allow the solution to completely dry on skin prior to needle placement (2-3 min). Care should be taken to avoid needle or catheter contamination from chlorhexidine spraying or dripping, or from applicator device disposal, onto aseptic work surfaces. (Class II) 


\section{Neuraxial Procedures on Anesthetized or Deeply Sedated Patients}

"We define the anesthetized patient as one who is under general anesthesia. A deeply sedated patient is one who is sedated to the point of being unable to recognize and/or report any sensation that the physician would interpret as atypical during block placement." 3 In either case, the patient's state of wakefulness is insufficient to support cognizance of potentially deleterious events during the procedure. The appropriateness of performing regional anesthesia and interventional pain medicine procedures in unresponsive patients continues to be debated. Indeed, this topic is an outstanding example of how individuals of similar expertise can arrive at different recommendations after review of the same, albeit limited, data set. For example, some European experts endorse (particularly peripheral) regional blockade in anesthetized or deeply sedated patients, ${ }^{159,160}$ whereas the majority of North American experts advise against this practice in adult patients.

We previously reviewed the pathophysiology of this issue in detail. A substantial body of literature points to divergent descriptions of how patients report needle-to-spinal cord contact. Some reports describe paresthesia or abnormal sensation when a needle enters the spinal cord, especially if accompanied by injection; injury, if it occurred at all, often was associated with these warning signs. Conversely, there also exist reports of fully awake or minimally sedated patients who sustained neuraxial injury but reported no unusual sensations during needle placement. ${ }^{2,3}$ Thus, one may argue that because "the neuroanatomy of the spinal cord and its coverings cannot be consistently relied upon to provide warning or indication of needle or catheter-induced trauma,"2,161 so too wakefulness cannot be relied upon as critical to the detection of impending injury. Nevertheless, our 2008 practice advisory categorized wakefulness as a potentially useful monitoring tool when used during adult, but not pediatric, neuraxial anesthesia, or pain medicine procedures. Importantly, wakefulness is not limited as a monitor of nerve injury but may also play a role in recognizing neuraxial-related complications such as high spinal anesthesia or evolving local anesthetic systemic toxicity. ${ }^{30,162}$

\section{Neuraxial Anesthesia in the Anesthetized or Deeply Sedated Pediatric Patient}

Although the absolute risks in either scenario are unknown, as stated in our 2008 practice advisory, "the argument to perform neuraxial anesthesia in anesthetized or deeply sedated children is predicated on the likely higher risk of injuring a moving and/or uncooperative child during placement of a neuraxial-directed needle versus the (presumably) much lower risk of injuring the spinal cord even in the absence of patient feedback."3 Emerging data from large-scale pediatric registries have strengthened the evidence base for our previous recommendation. These large registries - 2 from the French-Language Society of Pediatric Anaesthesiologists ${ }^{163,164}$ and one each from the Association of Pediatric Anaesthetists of Great Britain and Ireland ${ }^{165}$ and the (North American) Pediatric Regional Anesthesia Network $(\text { PRAN })^{166,167}$-include more than 100,000 pediatric patients who underwent some form of regional anesthesia, with more than $95 \%$ of these procedures performed under general anesthesia. The strengths of these studies include their large numbers, relatively robust follow-up, and practitioner experience. The weaknesses include a large number of caudal anesthetics and admixing of an increasing number of peripheral nerve blocks. Nevertheless, overall analysis points to very few long-term neuraxial injuries, with an incidence similar to the "expected" 0 to 2 injuries per 10,000 blocks. Thus, performing neuraxial regional blockade in anesthetized pediatric patients does not appear to place these patients at increased risk of injury that is higher than baseline expectation. Indeed, there is some evidence that general anesthesia may reduce some injuries as compared with those recorded in awake children. ${ }^{167}$ Nevertheless, these data should not be interpreted as a license to lower one's vigilance during these procedures. A case series described 3 permanent neuraxial injuries and 1 unrecognized high spinal anesthetic in children who had thoracic epidural anesthesia placed during general anesthesia by experienced pediatric anesthesiologists. ${ }^{30}$ These cases emphasize that neuraxial procedures carry inherent risk regardless of patient wakefulness.

\section{Neuraxial Anesthesia in the Anesthetized or Deeply Sedated Adult Patient}

Just as new data are supportive of our previous recommendations regarding pediatric patients, our 2008 recommendation to not routinely perform neuraxial regional anesthesia in anesthetized or deeply sedated adults gained further support from the ASA Closed Claims project. ${ }^{110}$ An analysis of injuries associated with cervical procedures for chronic pain noted that general anesthesia or deep sedation was used in $67 \%$ of those cervical procedure claims wherein the cervical spinal cord sustained injury, but only $19 \%$ of those cervical procedure claims that were not associated with cord injury. Of those patients who were nonresponsive during the cervical procedure, $25 \%$ sustained injury to their cervical spinal cord. This is compared with only $5 \%$ of responsive patients sustaining a cord injury associated with their

TABLE 6. Recommendations: Performing Neuraxial Techniques in Anesthetized or Deeply Sedated* Patients

These recommendations are intended to encourage optimal patient care, but cannot ensure the avoidance of adverse outcomes. As with any practice advisory recommendation, these are subject to revision as knowledge advances regarding specific complications.

- Monitoring and prevention: There are no data to support the concept that ultrasound guidance of needle placement reduces the risk of neuraxial injury in patients under general anesthesia or deep sedation. (Class II)

- Adult neuraxis: Warning signs such as paresthesia or pain on injection of local anesthetic inconsistently herald needle contact with the spinal cord. Nevertheless, some patients do report warning signs of needle-to-neuraxis proximity. General anesthesia or deep sedation removes any ability for the patient to recognize and report warning signs. This suggests that neuraxial regional anesthesia or interventional pain medicine procedures should be performed rarely in adult patients whose sensorium is compromised by general anesthesia or deep sedation. Adult patients with specific conditions (eg, developmental delay, multiple bone trauma) may be appropriate exceptions to this recommendation after consideration of risk versus benefit. (Class III)

- Pediatric neuraxis: The benefit of ensuring a cooperative and immobile infant or child likely outweighs the risk of performing neuraxial regional anesthesia in pediatric patients during general anesthesia or deep sedation. The overall risk of neuraxial anesthesia should be weighed against its expected benefit. (Class I)

*Anesthetized refers to patients under general anesthesia. Deep sedation is defined as the patient being sedated to the point of being unable to recognize and/or report any sensation that the physician would interpret as atypical during block placement.

Recommendations contained within Table 6 have been modified from our 2008 advisory. ${ }^{3}$ Significant changes are in italics. 
cervical procedure. While analysis of legal claims can establish neither incidence nor cause and effect, this information nevertheless suggests that conducting neuraxial procedures (at least around the cervical spine) in unresponsive patients may increase the likelihood of subsequent neuraxial injury.

An often-misunderstood recommendation from our 2008 practice advisory was that interscalene blocks not be performed routinely in anesthetized or deeply sedated adults or children. We speculate that confusion on this topic occurred because the recommendation was based on medicolegal concerns rather than specific scientific evidence that interscalene blocks per se are more or less risky than other peripheral nerve blocks in anesthetized or deeply sedated patients. Our primary intent was to emphasize the existence of literature that describes cervical spinal cord injury in patients who underwent interscalene block during general anesthesia and sustained significant cervical spinal cord injury. ${ }^{168}$ Whether general anesthesia was a contributor to these injuries will never be known with certainty, but a similar body of "plaintiff-friendly" literature does not exist for other blocks. In the interim since our last advisory, the PRAN registry reported no postoperative neurologic symptoms associated with 390 pediatric interscalene blocks (upper limit of $95 \%$ confidence interval, $0.77 \%) .{ }^{169}$ This report appears to corroborate findings from recent pediatric regional anesthesia registries - that regional blocks in anesthetized or deeply sedated children may be no more risky that regional anesthesia in awake adults. However, the number of interscalene blocks reported in PRAN is insufficient for us to make a definitive recommendation on this issue.

Recommendations for performing procedures on anesthetized or deeply sedated patients are summarized in Table 6 .

\section{Summary}

This practice advisory offers additional information and recommendations on selected topics from our 2008 advisory. Despite this new information, our summary of the topic has not changed: "The pathophysiology of neuraxis injury associated with regional anesthesia and pain medicine procedures presumes that a mechanical, vascular, neurotoxic, or a combination insult has occurred. With the exception of epidural hematoma or abscess, the linkage of patient injury to a specific anesthetic procedure or perioperative event is mostly one of association rather than causation. Importantly, many of the factors that may contribute to neuraxis injury cannot be identified prospectively, which suggests that a large portion of these injuries are unpreventable based on our current knowledge. Fortunately, neuraxis injuries associated with regional anesthesia or pain medicine procedures are exceedingly rare."

\section{REFERENCES}

1. Kahn R, Gale EA. Gridlocked guidelines for diabetes. Lancet. 2010; 375:2203-2204.

2. Neal JM. Anatomy and pathophysiology of spinal cord injuries associated with regional anesthesia and pain medicine. Reg Anesth Pain Med. 2008;33:423-434.

3. Bernards CM, Hadzic A, Suresh S, Neal JM. Regional anesthesia in anesthetized or heavily sedated patients. Reg Anesth Pain Med. 2008;33: $449-460$

4. US Department of Health and Human Services Agency for Health Care Policy and Research. Acute pain management: operative or medical procedures and trauma. The Agency. Clinical practice guideline no. 1; no. 92-0023-0107. 1993.

5. ASA Standards, Guidelines, Statements and Practice Parameters. Available at: http://www.asahq.org/resources/clinical-information. Accessed January 21, 2015.
6. Neal JM, Bernards CM, Hadzic A, et al. ASRA Practice Advisory on neurologic complications in regional anesthesia and pain medicine. Reg Anesth Pain Med. 2008;33:404-422.

7. Lee LA, Posner KL, Domino KB, Caplan RA, Cheney FW. Injuries associated with regional anesthesia in the 1980s and 1990s. Anesthesiology. 2004;101:143-152.

8. Horlocker TT, Wedel DJ, Rowlingson JC, et al. Regional anesthesia in the patient receiving antithrombotic or thrombolytic therapy: American Society of Regional Anesthesia and Pain Medicine Evidence-Based Guidelines (third edition). Reg Anesth Pain Med. 2010;35:64-101.

9. Hebl J. Importance and implications of aseptic techniques during regional anesthesia. Reg Anesth Pain Med. 2006;31:311-323.

10. Rathmell JP, Lake T, Ramundo MB. Infectious risks of chronic pain treatments: injection therapy, surgical implants, and intradiscal techniques. Reg Anesth Pain Med. 2006;31:346-352.

11. Wedel DJ, Horlocker TT. Regional anesthesia in the febrile or infected patient. Reg Anesth Pain Med. 2006;31:324-333.

12. Moen V, Dahlgren N, Irestedt L. Severe neurological complications after central neuraxial blockades in Sweden 1990-1999. Anesthesiology. 2004;101:950-959.

13. de Sèze MP, Sztark F, Janvier G, Joseph PA. Severe and long-lasting complications of the nerve root and spinal cord after central neuraxial blockade. Anesth Analg. 2007;104:975-979.

14. Weed J, Finkel K, Beach ML, Granger CB, Gallagher JD, Sites BD. Spinal anesthesia for orthopedic surgery. A detailed video assessment of quality. Reg Anesth Pain Med. 2011;36:51-55.

15. Lee AJ, Ranasinghe JS, Chehade JM, et al. Ultrasound assessment of the vertebral level of the intercristal line in pregnancy. Anesth Analg. 2011;113:559-564.

16. Neal JM, Brull R, Chan VWS, et al. The ASRA evidence-based medicine assessment of ultrasound-guided regional anesthesia and pain medicine: executive summary. Reg Anesth Pain Med. 2010;35:S1-S9.

17. Chin KJ, Perlas A, Chan V, Brown-Shreves D, Koshkin A, Vaishnav V. Ultrasound imaging facilitates spinal anesthesia in adults with difficult surface anatomic landmarks. Anesthesiology. 2011;115:94-101.

18. Lirk P, Kolbitsch C, Putz G, et al. Cervical and high thoracic ligamentum flavum frequently fails to fuse in the midline. Anesthesiology. 2003;99: 1387-1390.

19. Kopp SL, Jacob AK, Hebl JR. Regional anesthesia in patients with preexisting neurologic disease. Reg Anesth Pain Med. 2015;40: 467-478.

20. Reina MA, Collier CB, Prats-Galino A. Unintentional subdural placement of epidural catheters during attempted epidural anesthesia: an anatomic study of spinal subdural compartment. Reg Anesth Pain Med. 2011; 36:537-541.

21. Hirabayashi Y, Saitoh K, Fukuda H, Igarashi T, Shimizu R, Seo N. Magnetic resonance imaging of the extradural space of the thoracic spine. Br J Anaesth. 1997;79:563-566.

22. Hogan QH. Epidural anatomy examined by cryomicrotome section. Influence of age, vertebral level, and disease. Reg Anesth. 1996;21: 395-406.

23. Grubbs PE Jr, Marini C, Toporoff B, et al. Somatosensory evoked potentials and spinal cord perfusion pressure are significant predictors of postoperative neurologic dysfunction. Surgery. 1988;104:216-223.

24. Hebl JR, Niesen AD. Infectious complications of regional anesthesia. Curr Opin Anaesthesiol. 2011;24:573-580.

25. Usubiaga JE, Usubiaga LE, Brea LM, Goyena R. Effect of saline injections on epidural and subarachnoid space pressures and relation to postspinal anesthesia headache. Anesth Analg. 1967;46:293-296.

26. Vas L, Raghavendran S, Hosalkar H, Patil B. A study of epidural pressures in infants. Paediatr Anaesth. 2001;11:575-583. 
27. Usubiaga JE, Wikinski JA, Usubiaga LE. Epidural pressure and its relation to spread of anesthetic solutions in epidural space. Anesth Analg. 1967;46:440-446.

28. Shields DC, Palma C, Khoo LT, Ferrante FM. Extramedullary intrathecal catheter granuloma adherent to the conus medullaris presenting as cauda equina syndrome. Anesthesiology. 2005;102:1059-1061.

29. Reina MA, Franco CD, López A, DéAndrés JA, van Zundert A. Clinical implications of epidural fat in the spinal canal. A scanning electron microscopic study. Acta Anaesthesiol Belg. 2009;60:7-17.

30. Meyer MJ, Krane EJ, Goldschneider KR, Klein NJ. Neurological complications associated with epidural analgesia in children: a report of 4 cases of ambiguous etiologies. Anesth Analg. 2012;115:1365-1370.

31. Roberts DR, Roe J, Baudouin C. Hyperlordosis as a possible factor in the development of spinal cord infarction. Br J Anaesth. 2003;90: 797-800.

32. Neal JM, Rathmell JP. Complications in Regional Anesthesia and Pain Medicine. 2nd ed. Philadelphia, PA: Lippincott Williams \& Wilkins; 2013.

33. Elahi F, Wu WY, Callahan D, Bhandary AK, Beutler BC, Lassalle CA Images in anesthesiology: reversible anterior spinal artery spinal artery syndrome during celiac plexus block. Anesthesiology. 2013;118:187.

34. Wulf H. Epidural anaesthesia and spinal haematoma. Can J Anaesth. 1996;43:1260-1271.

35. Kopp SL, Peters SM, Rose PS, Hebl JR, Horlocker TT. Worsening of neurologic symptoms after spinal anesthesia in two patients with spinal stenosis. Reg Anesth Pain Med. 2015;40 502-505.

36. Hampl KF, Schneider MC, Drasner K. Toxicity of spinal anesthetics. Curr Opin Anaesthesiol. 1999;12:559-564.

37. Markman JD, Guad KG. Lumbar spinal stenosis in older adults: current understanding and future directions. Clin Geriatr Med. 2008; 24:369-388

38. Hogan Q. Distribution of solution in the epidural space: examination by cryomicrotome section. Reg Anesth Pain Med. 2002;27:150-156.

39. Issack PS, Cunningham ME, Pumberger M, Hughes AP, Cammisa FP. Degenerative lumbar spinal stenosis. Evaluation and management. J Am Acad Orthop Surg. 2012;20:527-535.

40. Kalichman L, Cole R, Kim DH, et al. Spinal stenosis prevalence and associated symptoms: the Framingham Study. Spine J. 2008;9: $545-550$.

41. Yuen EC, Layzer RB, Weitz SR, Olney RK. Neurologic complications of lumbar epidural anesthesia and analgesia. Neurology. 1995;45: 1795-1801.

42. Moen V, Irestedt L. Neurological complications following central neuraxial blockades in obstetrics. Curr Opin Anaesthesiol. 2008;21: 275-280.

43. Pitkänen MT, Aromaa U, Cozanitis DA, Förster JG. Serious complications associated with spinal and epidural anaesthesia in Finland from 2000 to 2009. Acta Anaesthesiol Scand. 2013;57:553-564.

44. Hebl JR, Horlocker TT, Kopp SL, Schroeder DR. Neuraxial blockade in patients with preexisting spinal stenosis, lumbar disk disease, or prior spine surgery: efficacy and neurologic complications. Anesth Analg. 2010;111:1511-1519.

45. Beloeil H, Albaladejo P, Hoen S, Eschwege P, Benhamou D. Bilatera lower limb hypoesthesia after radical prostatectomy in the hyperlordotic position under general anesthesia. Can J Anaesth. 2003;50:653-656.

46. Lewandrowski KU, McLain RF, Lieberman I, Orr D. Cord and cauda equina injury complicating elective orthopedic surgery. Spine (Phila Pa 1976). 2006;31:1056-1059.

47. Upton AR, McComas AJ. The double crush in nerve entrapment syndromes. Lancet. 1973;2:359-362.
48. Drummond JC, Krane EJ, Tomatsu S, Theroux MC, Lee RR. Paraplegia after epidural-general anesthesia in a Morquio patient with moderate thoracic spinal stenosis. Can J Anaesth. 2015;62:45-49.

49. Nedeltchev K, Loher TJ, Stepper F, et al. Long-term outcome of acute spinal cord ischemia syndrome. Stroke. 2004;35:560-565.

50. Hickey R, Albin MS, Bunegin L, Gelineau J. Autoregulation of spinal cord blood flow: is the cord a microcosm of the brain? Stroke. 1986; 17:1183-1189.

51. Mashour GA, Shanks AM, Kheterpal S. Perioperative stroke and associated mortality after noncardiac, nonneurologic surgery. Anesthesiology. 2011;114:1289-1296.

52. Bernard JM, Passuti N, Pinaud M. Long-term hypotensive technique with nicardipine and nitroprusside during isoflurane anesthesia for spinal surgery. Anesth Analg. 1992;75:179-185.

53. Sharrock NE, Ranawat CS, Urquhart B, Peterson M. Factors influencing deep vein thrombosis following total hip arthroplasty under epidura anesthesia. Anesth Analg. 1993;76:765-771.

54. Sum DC, Chung PC, Chen WC. Deliberate hypotensive anesthesia with labetalol in reconstructive surgery for scoliosis. Acta Anaesthesiol Scand. 1996;34:203-207.

55. Tsuji T, Matsuyama Y, Sato K, Iwata H. Evaluation of spinal cord blood flow during prostaglandin $\mathrm{E}_{1}$-induced hypotension with power Doppler ultrasonography. Spinal Cord. 2001;39:31-36.

56. Duggal N, Lach B. Selective vulnerability of the lumbosacral spinal cord after cardiac arrest and hypotension. Stroke. 2002;33:116-121.

57. Weidauer S, Nichtweiss M, Lanfermann H, Zanella RE. Spinal cord infarction: MR imaging and clinical features in 16 cases. Neuroradiology. 2002;44:851-857.

58. Cole DJ, Lin DM, Drummond JC, Shapiro HM. Spinal tetracaine decreases central nervous system metabolism during somatosensory stimulation in the rat. Can J Anaesth. 1990;37:231-237.

59. Crosby G. Local spinal cord blood flow and glucose utilization during spinal anesthesia with bupivacaine in conscious rats. Anesthesiology. $1985 ; 63: 55-60$.

60. Crosby G, Russo MA, Szabo MD, Davies KR. Subarachnoid clonidine reduces spinal cord blood flow and glucose utilization in conscious rats. Anesthesiology. 1990;73:1179-1185.

61. Iida H, Iida M. Effects of spinal analgesics on spinal circulation: the safety standpoint. J Neurosurg Anesthesiol. 2008;20:180-187.

62. Lanier WL. The history of neuroanesthesiology: the people, pursuits, and practices. J Neurosurg Anesthesiol. 2012;24:281-299.

63. Neal JM. Effects of epinephrine in local anesthetics on the central and peripheral nervous systems: neurotoxicity and neural blood flow. Reg Anesth Pain Med. 2003;28:124-134.

64. Edvinsson L, MacKenzie ET, McCulloch J. Cerebral Blood Flow and Metabolism. New York: Raven Press; 1993.

65. Pohl A, Cullen DJ. Cerebral ischemia during shoulder surgery in the upright position: a case series. J Clin Anesth. 2005;17:463-469.

66. Drummond JC, Lee RR, Owens EL. Spinal cord ischemia occurring in association with induced hypotension for colonic surgery. Anesth Analg. 2012:114:1297-1300

67. Drummond JC. The lower limit of autoregulation: time to revise our thinking? Anesthesiology. 1997;86:1431-1433.

68. Kobrine AI, Doyle TF, Martins AN. Autoregulation of spinal cord blood flow. Clin Neurosurg. 1975;22:573-581

69. Joshi B, Ono M, Brown C, et al. Predicting the limits of cerebral autoregulation during cardiopulmonary bypass. Anesth Analg 2012;114:503-510

70. Laflam A, Joshi B, Brady K, et al. Shoulder surgery in the beach chair position is associated with diminished cerebral autoregulation but no differences in postoperative cognition or brain injury biomarker levels 
compared with supine positioning: the Anesthesia Patient Safety Foundation Beach Chair Study. Anesth Analg. 2015;120:176-185.

71. Bijker JB, Persoon S, Peelen LM, et al. Intraoperative hypotension and perioperative ischemic stroke after general surgery. A nested case-control study. Anesthesiology. 2012;116:658-664.

72. Drummond JC. A beach chair, comfortably positioned atop an iceberg. Anesth Analg. 2013;116:1204-1206.

73. Drummond JC, Lee RR, Howell JP Jr. Focal cerebral ischemia after surgery in the "beach chair" position: the role of a congenital variation of circle of Willis anatomy. Anesth Analg. 2012;114:1301-1303.

74. Dohi S, Takeshima R, Naito H. Spinal cord blood flow during spinal anesthesia in dogs: the effects of tetracaine, epinephrine, acute blood loss, and hypercapnia. Anesth Analg. 1987;66:599-606.

75. Vitale MG, Moore DW, Matsumoto H, et al. Risk factors for spinal cord injury during surgery for spinal deformity. J Bone Joint Surg Am. 2010;92:64-71

76. Lam AM, Baldwin G. Blood pressure and adverse perioperative neurologic outcomes: an uncomfortable position. Anesth Analg. 2012; 114:1156-1159.

77. Pin-on P, Schroeder D, Munis J. The hemodynamic management of 5,177 neurosurgical and orthopedic patients who underwent surgery in the sitting or "beach chair" position without incidence of adverse neurologic events. Anesth Analg. 2013;116:1317-1324.

78. Ya Deau JT, Liu SS, Bang H, et al. Cerebral oximetry desaturation during shoulder surgery performed in a sitting position under regional anesthesia. Can J Anaesth. 2011;58:986-992.

79. YaDeau JT, Casciano M, Liu SS, et al. Stroke, regional anesthesia in the sitting position, and hypotension. A review of 4169 ambulatory surgery patients. Reg Anesth Pain Med. 2011;36:430-435.

80. Sharrock NE, Beksac B, Flynn E, Go G, Della Valle AG. Hypotensive epidural anaesthesia in patients with preoperative renal dysfunction undergoing hip replacement. Br J Anaesth. 2006;96:207-212.

81. Sharrock NE, Fisher G, Flynn E, Go G, Sculco TP, Salvati EA. The early recovery of cognitive function after total-hip replacement under hypotensive epidural anesthesia. Reg Anesth Pain Med. 2005;30:123-127.

82. Sharrock NE, Salvati EA. Hypotensive epidural anesthesia for total hip arthroplasty: a review. Acta Orthop Scand. 1996;67:91-107.

83. Sharrock NE, Go G, Mineo R, Harpel PC. The hemodynamic and fibrinolytic response to low dose epinephrine and phenylephrine infusions during total hip replacement under epidural anesthesia. Thromb Haemost. 1992;68:436-441

84. Kennedy WF Jr, Bonica JJ, Ward RJ, Tolas AG, Martin WE, Grinstein A. Cardiorespiratory effects of epinephrine when used in regional anesthesia. Acta Anaesthesiol Scand. 1966;23:320-333.

85. Lennon RL, Hosking MP, Gray JR, Klassen RA, Popovsky MA, Warner MA. The effects of intraoperative blood salvage and induced hypotension on transfusion requirements during spinal surgical procedures. Mayo Clin Proc. 1987;62:1090-1094.

86. Mashour GA, Woodrum DT, Avidan MS. Neurological complications of surgery and anaesthesia. Br J Anaesth. 2015;114:194-203.

87. Wang YC, Huang SY, Lin HT, Chan KH, Tsou MY. Quadriplegia after parathyroidectomy in a hemodialysis patient. Acta Anaesthesiol Taiwan. 2011;49:32-34.

88. Kumral E, Polat F, Güllüoglu H, Uzunköprü C, Tuncel R, Alpaydin S. Spinal ischaemic stroke: clinical and radiological findings and short-term outcome. Eur J Neurol. 2011;18:232-239.

89. Cheshire WP, Santos CC, Massey EW, Howard JF Jr. Spinal cord infarction: etiology and outcome. Neurology. 1996;47:321-330.

90. Khan SN, Stansby G. Cerebrospinal fluid drainage for thoracic and thoracoabdominal aortic aneurysm surgery. Cochrane Database Syst Rev. 2012;10 CD003635.
91. Horlocker TT, Abel MD, Messick JM Jr, Schroeder DR. Small risk of serious neurologic complications related to lumbar epidural catheter placement in anesthetized patients. Anesth Analg. 2003;96:1547-1552.

92. Bydon M, Lin J, Macki M, Gokaslan ZL, Bydon A. The current role of steroids in acute spinal cord injury. World Neurosurg. 2014;82: 848-854.

93. Bracken MB. Steroids for acute spinal cord injury. Cochrane Database Syst Rev. 2012;10 CD001046.

94. Dearden NM, Gibson JS, McDowall DG, Gibson RM, Cameron MM. Effects of high-dose dexamethasone on outcome from severe head injury. J Neurosurg. 1986;64:81-88.

95. Norris JW. Steroid therapy in acute cerebral infarction. Arch Neurol. 1976;33:69-71.

96. Drummond JC, Moore SS. The influence of dextrose administration on neurologic outcome after temporary spinal cord ischemia in the rabbit. Anesthesiology. 1989;70:64-70.

97. Edwards P, Arango M, Balica L, et al. Final results of MRC CRASH, a randomised placebo-controlled trial of intravenous corticosteroids in adults with head injury-outcomes at 6 months. Lancet. 2005:1957-1959.

98. Wass CT, Lanier WL. Glucose modulation of ischemic brain injury: review and clinical recommendations. Mayo Clin Proc. 1996;71: 801-812.

99. Pasternak JJ, McGregor DG, Schroeder DR, et al. Hyperglycemia in patients undergoing cerebral aneurysm surgery: its association with long-term neurologic and neuropsychologic function. Mayo Clin Proc. 2008;83:406-417.

100. Walsh M, Devereaux PJ, Garg AX, et al. Relationship between intraoperative mean arterial pressure and clinical outcomes after noncardiac surgery: toward an empirical definition of hypotension. Anesthesiology. 2013;119:507-515.

101. Brady K, Hogue CW. Intraoperative hypotension and patient outcome: does "one size fit all"? Anesthesiology. 2013;119:495-497.

102. Drummond JC, Blake JL, Patel PM, Clopton P, Schulteis G. An observational study of the influence of "white-coat hypertension" on day-of-surgery blood pressure determinations. J Neurosurg Anesthesiol. 2013;25:154-161

103. Huntoon MA, Martin DP. Paralysis after transforaminal epidural injection and previous spinal surgery. Reg Anesth Pain Med. 2004;29:494-495.

104. Rathmell JP, April C, Bogduk N. Cervical transforaminal injection of steroids. Anesthesiology. 2004;100:1595-1600.

105. Rathmell JP, Benzon HT. Transforaminal injection of steroids: should we continue? Reg Anesth Pain Med. 2004;29:397-399.

106. Hoeft MA, Rathmell JP, Monsey RD, Fonda BJ. Cervical transforaminal injection and the radicular artery: variation in anatomical location within the cervical intervertebral foramina. Reg Anesth Pain Med. 2006;31:270-274.

107. Huntoon MA. Anatomy of the cervical intervertebral foramina: vulnerable arteries and ischemic neurologic injuries after transforaminal epidural injections. Pain. 2005;117:104-111.

108. Rathmell JP, Benzon HT, Dreyfuss P, et al. Safeguards to prevent neurologic complications after epidural steroid injections: consensus opinions from a multidisciplinary working group and national organizations. Anesthesiology. 2015;122:974-984.

109. Lee JH, Lee JK, Seo BR, Moon SJ, Kim JH, Kim SH. Spinal cord injury produced by direct damage during cervical transforaminal epidural injection. Reg Anesth Pain Med. 2008;33:377-379.

110. Rathmell JP, Michna E, Fitzgibbon DR, Stephens LS, Posner KL, Domino KB. Injury and liability associated with cervical procedures for chronic pain. Anesthesiology. 2011;114:918-926.

111. Beckman WA, Mendez RJ, Paine GF, Mazzilli MA. Cerebellar herniation after cervical transforaminal epidural injection. Reg Anesth Pain Med. 2006;31:282-285. 
112. Brouwers PJAM, Kottink EJBL, Simon MAM, Prevo RL. A cervica anterior spinal artery syndrome after diagnostic blockade of the right C6-nerve root. Pain. 2001;91:397-399.

113. Kim W, Kim JS, Lim SC, Kim YI, Moon DE. Reversible posterior leukoencephalopathy syndrome after cervical transforaminal epidural steroid injection presenting as transient blindness. Anesth Analg. 2011;112:967-970.

114. Ludwig MA, Burns SP. Spinal cord infarction following cervical transforaminal injection. A case report. Spine (Phila Pa 1976). 2005;30:E266-E268.

115. McMillan MR, Crumpton C. Cortical blindness and neurologic injury complicating cervical transforaminal injection for cervical radiculopathy. Anesthesiology. 2003;99:509-511.

116. Muro K, O’Shaughnessy B, Ganju A. Infraction of the cervical spinal cord following multilevel transforaminal epidural steroid injection: case report and review of the literature. J Spinal Cord Med. 2007;30: 385-388.

117. Scanlon GC, Moeller-Bertram T, Romanowsky SM, Wallace MS. Cervical transforaminal epidural steroid injections: more dangerous than we think? Spine (Phila Pa 1976). 2007;32:1249-1256.

118. Suresh S, Berman J, Connell DA. Cerebellar and brainstem infarction as a complication of CT-guided transforaminal cervical nerve root block. Skeletal Radiol. 2007;36:449-452.

119. Tiso RL, Cutler T, Catania JA, Whalen K. Adverse central nervous system sequelae after selective transforaminal block: the role of corticosteroids. Spine J. 2004;4:468-474.

120. Wallace MA, Fukui MB, Williams RL, Ku A, Baghai P. Complications of cervical selective nerve root blocks performed with fluoroscopic guidance. Am J Roentgenol. 2007;188:1218-1221.

121. Windsor RE, Strom S, Sugar R, Nagula D. Cervical transforaminal injection: review of the literature, complications, and a suggested technique. Pain Physician. 2003;6:457-465.

122. Chang Chien GC, Candido KD, Knezevic NN. Digital subtraction angiography does not reliably prevent paraplegia associated with lumbar transforaminal epidural steroid injection. Pain Physician. 2012;15:515-523.

123. Glaser SE, Falco F. Paraplegia following a thoracolumbar transforaminal epidural steroid injection. Pain Physician. 2005;8:309-314

124. Kennedy DJ, Dreyfuss P, Aprill C, Bogduk N. Paraplegia following image-guided transforaminal lumbar spine epidural steroid injection: two case reports. Pain Med. 2009;10:1389-1394.

125. Lyders EM, Morris PP. A case of spinal cored infarction following lumbar transforaminal epidural steroid injection: MR imaging and angiographic findings. AJNR Am J Neuroradiol. 2009;30:1691-1693.

126. Wybier M, Gaudart S, Petrover D, Houdart E, Laredo JD. Paraplegia complicating selective steroid injections of the lumbar spine. Report of five cases and review of the literature. Eur Radiol. 2009;20:181-189.

127. Benzon HT, Chew TL, McCarthy R, Benzon HA, Walega DR. Comparison of the particle sizes of the different steroids and the effect of dilution: a review of the relative neurotoxicities of the steroids. Anesthesiology. 2007;106:331-338.

128. Dawley JD, Moeller-Bertram T, Wallace MS, Patel PM. Intra-arterial injection in the rat brain. Evaluation of steroids used for transforaminal epidurals. Spine (Phila Pa 1976). 2009;34:1638-1643.

129. Okubadejo GO, Talcott MR, Schmidt RE, et al. Perils of intravascular methylprednisolone injection into the vertebral artery. An animal study. J Bone Joint Surg Am. 2008;90:1932-1938.

130. El-Yahchouchi C, Geske JR, Carter RE, et al. The noninferiority of the nonparticulate steroid dexamethasone and triamcinolone in lumbar transforaminal epidural steroid injections. Pain Med. $2013 ; 14: 1650-1657$
131. Kennedy DJ, Plastaras C, Casey E, et al. Comparative effectiveness of lumbar transforaminal epidural steroid injections with particulate versus nonparticulate corticosteroids for lumbar radicular pain due to intervertebral disc herniation: a prospective, randomized, double-blind trial. Pain Med. 2014;15:548-555.

132. Petterson CAV, Olsson Y. Blood supply of spinal nerve roots. An experimental study in the rat. Acta Neuropathol. 1989;78:455-461.

133. Hoy K, Hansen ES, He S-Z, et al. Regional blood flow, plasma volume, and vascular permeability in the spinal cord, the dural sac, and lumbar nerve roots. Spine (Phila Pa 1976). 1994;19:2804-2811.

134. Auroy Y, Narchi P, Messiah A, Litt L, Rouvier B, Samii K. Serious complications related to regional anesthesia. Results of a prospective survey in France. Anesthesiology. 1997;87:479-486.

135. Auroy Y, Benhamou D, Bargues L, et al. Major complications of regional anesthesia in France. The SOS regional anesthesia hotline service. Anesthesiology. 2002;97:1274-1280.

136. Rigler ML, Drasner K, Krejcie TC, et al. Cauda equina syndrome after continuous spinal anesthesia. Anesth Analg. 1991;72:275-281.

137. Staff NP, Engelstad J, Klein CJ, et al. Post-surgical inflammatory neuropathy. Brain. 2010;133:2866-2880.

138. Drasner K. Local anesthetic neurotoxicity and cauda equina syndrome. In: Neal JM,Rathmell JP. In: Complications in Regional Anesthesia and Pain Medicine. 2nd ed. Philadelphia, PA: Lippincott Williams \& Wilkins; 2013

139. Pollock JE. Transient neurologic symptoms: Etiology, risk factors, and management. Reg Anesth Pain Med. 2002;27:581-586.

140. Gissen AJ, Datta S, Lambert DH. The chloroprocaine controversy. I. Hypothesis to explain the neural complication of chloroprocaine epidural. Reg Anesth. 1984;9:124-134.

141. Gissen AJ, Datta S, Lambert DH. The chloroprocaine controversy. II. Is chloroprocaine neurotoxic? Reg Anesth. 1984;9:135-145.

142. Taniguchi M, Bollen AW, Drasner K. Sodium bisulfite: scapegoat for chloroprocaine neurotoxicity? Anesthesiology. 2004;100:85-91.

143. Yoos JR, Kopacz DJ. Spinal 2-chloroprocaine for surgery: an initial 10-month experience. Anesth Analg. 2005;100:553-558.

144. Vath JS, Kopacz DJ. Spinal 2-chloroprocaine: the effect of added fentanyl Anesth Analg. 2004;98:89-94.

145. Casati A, Danelli G, Berti M, et al. Intrathecal 2-chloroprocaine for lower limb outpatient surgery: a prospective, randomized, double-blind, clinical evaluation. Anesth Analg. 2006;103:234-238.

146. Casati A, Fanelli G, Danelli G, et al. Spinal anesthesia with lidocaine or preservative-free 2-chlorprocaine for outpatient knee arthroscopy: a prospective, randomized, double-blind comparison. Anesth Analg. 2007;104:959-964.

147. Hejtmanek MR, Pollock JE. Chloroprocaine for spinal anesthesia: a retrospective analysis. Acta Anaesthesiol Scand. 2011;55:267-272.

148. Vaghadia H, Neilson G, Lennox PH. Selective spinal anesthesia for outpatient transurethral prostatectomy (TURP): randomized controlled comparison of chloroprocaine with lidocaine. Acta Anaesthesiol Scand. 2012;56:217-223.

149. Lucas JS, Ducker TB, Perot PL Jr. Adverse reactions to intrathecal saline injections for control of pain. J Neurosurg. 1975;75:557-561

150. Rice L, Wee MYK, Thomson K. Obstetric epidurals and chronic adhesive arachnoiditis. Br J Anaesth. 2004;92:109-120.

151. Aromaa U, Lahdensuu M, Cozanitis DA. Severe complications associated with epidural and spinal anaesthesias in Finland 1987-1993. A study based on patient insurance claims. Acta Anaesthesiol Scand. 1997;41: 445-452.

152. Cook TM, Counsell D, Wildsmith JA. Royal College of Anaesthetists Third National Audit Project. Major complications of central neuraxial 
block: report of the Third National Audit Project of the Royal College of Anaesthetists. Br J Anaesth. 2009;102:179-190.

153. Scott DB, Hibbard BM. Serious non-fatal complications associated with extradural block in obstetric practice. Br J Anaesth. 1990;64:537-541.

154. Bogod D. The sting in the tail: antiseptics and the neuraxis revisited. Anaesthesia. 2012;67:1305-1308.

155. Killeen T, Kamat A, Walsh D, Parker A, Aliashkevich A. Severe adhesive arachnoiditis resulting in progressive paraplegia following obstetric spinal anaesthesia: a case report and review. Anaesthesia. 2012;67.

156. American Society of Anesthesiologists Task Force on Infectious Complications Associated With Neuraxial Techniques. Practice advisory for the prevention, diagnosis, and management of infectious complications associated with neuraxial techniques. Anesthesiology. 2010;112:530-545.

157. Sviggum HP, Jacob AK, Arendt KW, Mauermann ML, Horlocker TT, Hebl JR. Neurologic complications after chlorhexidine antisepsis for spinal anesthesia. Reg Anesth Pain Med. 2012;37:139-144.

158. Doan L, Piskoun B, Rosenberg AD, Blanck TJJ, Phillips MS, Xu F. In vitro antiseptic effects on viability of neuronal and Schwann cells. Reg Anesth Pain Med. 2012;37:131-138.

159. Feely NM, Popat MT, Rutter SV. Regional anaesthesia for limb surgery: a review of anaesthetists beliefs and practice in the Oxford region. Anaesthesia. 2008;63:621-625.

160. Kessler P, Steinfeldt T, Gogarten W, et al. Peripheral regional anesthesia in patients under general anesthesia: risk assessment with respect to paresthesia, injection pain and nerve damage [in German]. Anaesthesist. 2013;62:483-488

161. Krane EJ, Dalens BJ, Murat I, Murrell D. The safety of epidurals placed during general anesthesia. Reg Anesth Pain Med. 1998;23: 433-438.

162. Yanovski B, Gaitini L, Volodarski D, Ben-David B. Catastrophic complication for continuous peripheral nerve block analgesia. Anaesthesia. 2012;67:1166-1169.
163. Ecoffey C, Lacroix F, Giaufre E, Orliaguet G, Courreges P. Association des Anesthésistes Réanimateurs Pédiatriques d'Expression Française (ADARPEF). Epidemiology and morbidity of regional anesthesia in children: a follow-up one-year prospective survey of the French-Language Society of Paediatric Anaesthesiologists (ADARPEF). Paediatr Anaesth 2010;20:1061-1069.

164. Giaufré E, Dalens B, Gombert A. Epidemiology and morbidity of regional anesthesia in children: a one-year prospective survey of the French-Language Society of Pediatric Anesthesiologists. Anesth Analg. 1996;83:904-912.

165. Llewellyn N, Moriarty A. The national pediatric epidural audit. Paediatr Anaesth. 2007;17:520-533.

166. Polaner DM, Taenzer AH, Walker BJ, et al. Pediatric Regional Anesthesia Network (PRAN): a multi-institutional study of the use and incidence of complications of pediatric regional anesthesia. Anesth Analg. 2012;115:1353-1364.

167. Taenzer AH, Walker BJ, Bosenberg AT, et al. Asleep versus awake: does it matter?: Pediatric regional block complications by patient state: a report from the Pediatric Regional Anesthesia Network. Reg Anesth Pain Med. 2014;39:279-283.

168. Benumof JL. Permanent loss of cervical spinal cord function associated with interscalene block performed under general anesthesia. Anesthesiology. 2000;93:1541-1544.

169. Taenzer A, Walker BJ, Bosenberg AT, et al. Interscalene brachia plexus blocks under general anesthesia in children: is this safe practice? A report from the Pediatric Regional Anesthesia Network (PRAN). Reg Anesth Pain Med. 2014;39:502-505.

170. Eagle KA, Berger PB, Calkins H, et al. ACC/AHA guideline update for perioperative cardiovascular evaluation for noncardiac surgery- executive summary: a report of the American College of Cardiology/American Heart Association Task Force on Practice Guidelines (Committee to Update the 1996 Guidelines on Perioperative Cardiovascular Evaluation for Noncardiac Surgery). J Am Coll Cardiol. $2002 ; 39 \cdot 542-553$

\section{APPENDIX 1. Strength of Recommendations}

\section{Classification}

Class I Animal and/or human evidence and/or general agreement of expert opinion support the effectiveness and usefulness of the recommendation.

Class II The weight of conflicting evidence and/or the weight of expert opinion support the usefulness of the recommendation.

Class III

The usefulness of the recommendation is limited by absent or conflicting evidence and/or divergent expert opinion.

This classification system is significantly modified from the American College of Cardiology/American Heart Association construct for classifying strength of evidence. ${ }^{170}$ 